\title{
Aging, Subjective Experience, and Cognitive Control: Dramatic False Remembering by Older Adults
}

\author{
Larry L. Jacoby, Anthony J. Bishara, Sandra Hessels, and Jeffrey P. Toth \\ Washington University
}

\begin{abstract}
Recent research suggests that older adults are more susceptible to interference effects than are young adults; however, that research has failed to equate differences in original learning. In 4 experiments, the authors show that older adults are more susceptible to interference effects produced by a misleading prime. Even when original learning was equated, older adults were 10 times as likely to falsely remember misleading information and were much less likely to increase their accuracy by opting not to answer under conditions of free responding. The results are well described by a multinomial model that postulates multiple modes of cognitive control. According to that model, older adults are likely to be captured by misleading information, a form of goal neglect or deficit in inhibitory functions.
\end{abstract}

A potential consequence of age-related declines in memory is older adults' greater susceptibility to scams (Jacoby, 1999). In one scam, for example, an unscrupulous repairman attempts to overcharge an older adult by falsely claiming, "I told you that it would cost $X$ [a much higher price than was originally quoted], and you agreed to pay." The scam is most effective if its victim falsely remembers having agreed to pay the much higher price. In this article, we report results suggesting that such a possibility is quite real—a misleading prime, akin to a false "I told you" claim, can result in older adults showing levels of false remembering that are dramatically higher than those shown by young adults.

The scam we have detailed can be described as a misinformation effect. Misinformation effects occur when false information presented after a critical event distorts or impairs memory reports about that event (see Ayers \& Reder, 1998, for a review). In Loftus's (1975) classic misinformation experiments, for example, participants first viewed an accident scene that included a stop sign and were later asked a misleading question that, instead, implied the presence of a yield sign. Participants in this condition were much more likely to mistakenly report that a yield sign had appeared in the earlier scene than participants in a control condition, who were not asked the misleading question. In general, the evidence indicates that older adults are more vulnerable to misinformation effects than are young adults (e.g., G. Cohen \& Faulkner, 1989; Karpel, Hoyer, \& Toglia, 2001). Moreover, many of the factors proposed to underlie misinformation effects in the young-including poor memory for the original event (Belli, Windschitl, McCarthy, \& Winfrey, 1992), blocked memory access (e.g., Bekerian \& Bowers, 1983), source confusion (e.g., Lindsay \& Johnson, 1989), and reliance on gist (e.g., Brainerd \& Reyna,

Larry L. Jacoby, Anthony J. Bishara, Sandra Hessels, and Jeffrey P. Toth, Department of Psychology, Washington University.

This research was supported by National Institute on Aging Grant AG13845. We are grateful to Carole Jacoby for assistance during all phases of the research reported here.

Correspondence concerning this article should be addressed to Larry L. Jacoby, Department of Psychology, Washington University, St. Louis, MO 63130. E-mail: 1ljacoby@artsci.wustl.edu
1998) - appear to generally characterize the memory functioning of older adults (for reviews, see Balota, Dolan, \& Duchek, 2000; Zacks, Hasher, \& Li, 2000).

The present article examines the utility of a dual-process approach for understanding age differences in misinformation effects of the sort engendered by "I told you" claims. In particular, we distinguish between recollection and automatic influences of memory and argue that separating the contributions of these two bases for responding can provide a useful perspective for understanding misinformation effects. Recollection refers to a consciously controlled use of memory for a prior event and is assumed to be independent of more automatic forms or uses of memory. As we describe, prior research using our dual-process approach has suggested that age-related differences in proactive interference (PI) may be completely accounted for by age-related declines in recollection (Hay \& Jacoby, 1999; Jacoby, Debner, \& Hay, 2001).

In the experiments reported here, we use a priming paradigm to examine effects on cued recall. The effects of a misleading prime are meant to mimic those of misleading "I told you" claims and to be similar to effects found in misinformation paradigms (e.g., Loftus, 1975). We find evidence of age differences that go beyond those attributable to declines in recollection. We propose an expanded version of our dual-process model to account for these new findings and test the fit of that model using subjective-report measures of memory (cf. Gardiner \& Richardson-Klavehn, 2000) and memory tests that allow free versus forced responding (cf. Koriat \& Goldsmith, 1994, 1996). Our goal is to develop a relatively simple model that specifies the bases for age differences in interference effects. Better specification of age-related memory deficits is important both for improving the diagnosis of such deficits and for the development of training procedures to ameliorate those deficits (e.g., Jacoby, Jennings, \& Hay, 1996).

\section{Interference Effects Due to Differences in Original Learning}

Evidence that misinformation effects are larger in older adults compared with young adults (e.g., G. Cohen \& Faulkner, 1989; Karpel et al., 2001) is consistent with the belief that older adults 
are more vulnerable to interference effects-a belief that was once widely held, was rejected, and has now regained popularity. Results from early retroactive interference (RI) and PI experiments were treated as compelling evidence of age differences in susceptibility to interference (for reviews, see Arenberg, 1973; Welford, 1958). However, those early experiments were later criticized for failing to equate original learning for the two age groups. Researchers argued that, rather than reflecting increased susceptibility to interference, age-related differences in performance might instead reflect differences in the ability to acquire new information. In fact, when the level of original learning was equated, age differences in PI and RI were largely eliminated (for reviews, see Craik, 1977; Kausler, 1991).

Similarly, age differences in misinformation effects might reflect differences in original learning. Investigations revealing larger misinformation effects for older adults have not equated original learning (e.g., G. Cohen \& Faulkner, 1989). Further, evidence that misinformation effects are larger when memory for the original event is poor (e.g., Belli et al., 1992) are consistent with the possibility that the larger misinformation effects apparent for older adults result from these individuals' poorer memory for the original event. In the experiments reported here, we equate original learning for young and older adults by allowing additional study time for older adults.

\section{Age Differences in Interference Effects Due to Differences in Recollection and Capture}

In the dual-process approach, recollection and accessibility bias serve as alternative bases for cued recall (Figure 1A). When people are unable to recollect a past event, they guess with the first response that comes to mind, thereby showing effects of accessibility bias. Thus, this account suggests two possible reasons for changes in interference effects across age groups. First, increased interference may result from a decrease in the ability to recollect a target event without a corresponding change in accessibility bias. Second, increased interference may result from an increase in the accessibility of interfering or invalid information without a corresponding change in recollection of the target event (cf. McCloskey \& Zaragoza, 1985).

To test these ideas, Jacoby et al. (2001) manipulated accessibility bias in an initial training phase by exposing young and older adults to pairs of associatively related words. Each cue word was paired with two different responses, and the probability of each pairing was varied over trials. For example, the typical response bone might appear with the cue word knee on $75 \%$ of the training trials, whereas the atypical response bend appeared with the cue on only $25 \%$ of the trials. For a baseline condition, the two cueresponse pairs were presented equally often. After training, participants were presented with short lists of to-be-remembered pairs (e.g., knee bone), followed by a cued-recall test for those pairs. Test trials consisted of a cue word coupled with a fragmented version of the response (e.g., knee $b_{-} n_{-}$); the fragment could be completed with either of the two responses that had been paired with the cue during the training phase (e.g., bend or bone). Participants were instructed to complete the fragment with the response presented in the immediately preceding study list, guessing if necessary.

For the valid training condition, the response presented in the study list was the one presented most frequently during training (e.g., bone), which caused recollection and accessibility to yield the same response. As shown in Figure 1A, correct recall could result either from recollection of the studied word or, when recollection failed, from reliance on the accessibility bias developed during training. For the invalid training condition, in contrast,

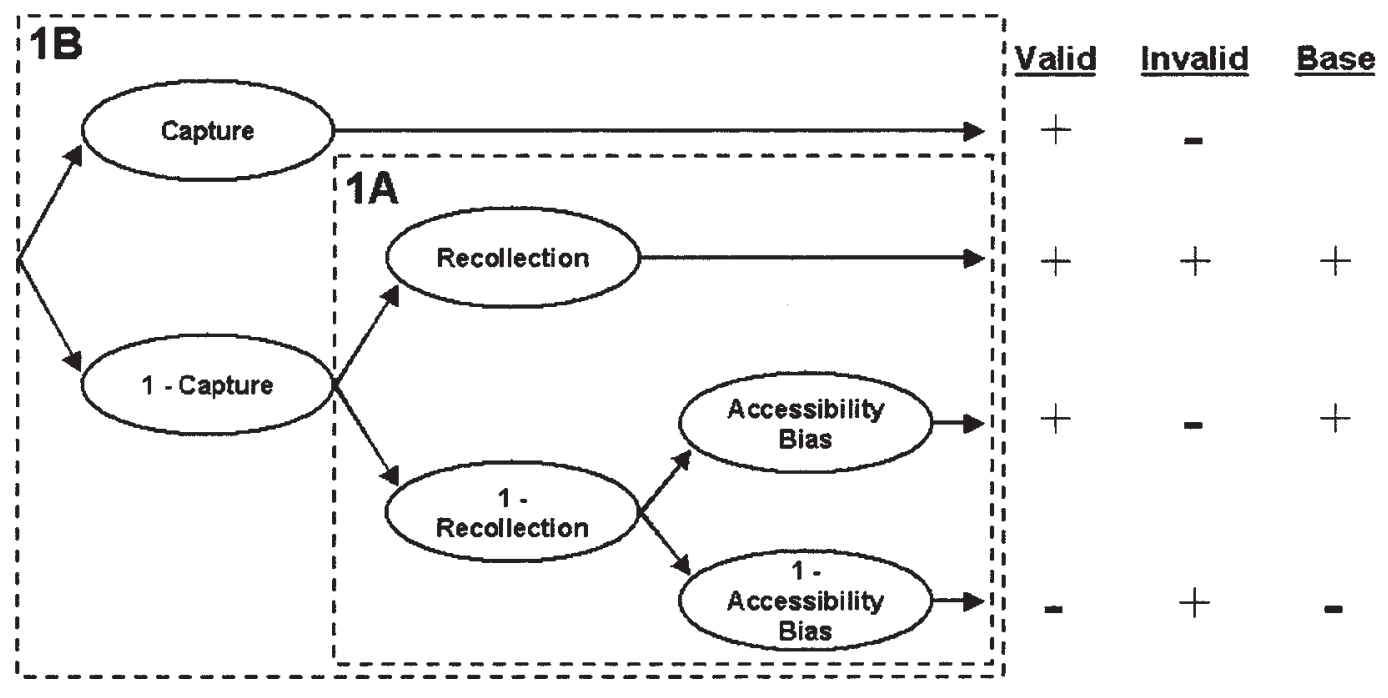

Figure 1. General form of the multinomial models used in the present research. Figure 1A shows the recollection/accessibility-bias model used to fit performance in Jacoby et al. (2001) and for young adults' performance in the present experiments. Figure 1B shows the capture model used to fit both the young and the older adults' performance in the present experiments. Branches lead to correct recall $(+)$ and false recall $(-)$ for valid, invalid (misleading), and baseline prime conditions. Note that the models presented here are simplified for illustrative purposes; the full models used for data fitting are presented in Figure 2. 
accessibility bias and recollection were placed in opposition in that participants studied the response presented least frequently during training (e.g., bend). For these pairs, false recall (e.g., saying "bone" when bend was studied) occurred when participants failed to recollect the study pair but instead relied on accessibility.

Jacoby et al. (2001) reported that aging decreased individuals' ability to recollect, thereby increasing observed PI, but left estimates of accessibility bias unchanged. Similarly, dividing attention during study or minimizing presentation durations reduced young adults' ability to recollect, thereby increasing observed PI, but left accessibility bias unchanged. Manipulating accessibility bias by means of training left recollection unchanged and had effects on PI that were the same for young and older adults, showing that age differences in susceptibility to interference were not because of differences in accessibility bias.

Results reported by Jacoby et al. (2001) show that age-related declines in recollection sometimes completely account for older adults' greater susceptibility to interference. However, in other cases, changes in recollection may be insufficient to account for elevated interference effects in older adults. For example, failures to inhibit prepotent, automatic responses (e.g., Hasher \& Zacks, 1988) may constitute an alternative source of age-related increases in interference. Such failures might not have been detected by Jacoby et al. because their procedures did not produce prepotent responses that had to be inhibited.

In the present experiments, we combine the recollectionaccessibility-bias (RA) and inhibition-deficit models examined by Jacoby et al. (2001) to account for age-related differences in misinformation effects that cannot be accounted for by the simpler RA model. The combined model (Figure 1B) differs from the simpler model (Figure 1A) only in that a capture parameter precedes recollection. Capture may reflect a failure to inhibit the misleading or invalid information (cf. Hasher \& Zacks, 1988) or, alternatively, may be a form of goal neglect (e.g., Duncan, 1995; Duncan, Emslie, Williams, Johnson, \& Freer, 1996). The notion is that being captured by a highly accessible response eliminates the opportunity to engage in recollection in the same way that, in the Stroop task, reading the irrelevant word eliminates the opportunity to name the color in which that word is printed (Lindsay \& Jacoby, 1994). Older adults might sometimes be captured by misleading information and accept it as being veridical without further attempts at recollection.

Again, in the memory scam example we have given, older adults might mistakenly accept a misleading "I told you" claim as true and perhaps even falsely remember having been told the false information. An effect of this sort is reflected in the capture parameter. Alternatively, the older person might attempt to recollect what he or she was earlier told but, being unable to do so, accept the false claim because of its high accessibility, perhaps even knowing that his or her response is just a guess. An effect of that sort is reflected in the accessibility bias parameter. Our experiments examine age differences in the loci of interference effects in cued-recall performance along with age differences in subjective experience. We also investigate age differences in interference effects using tests of recognition memory. As we describe, comparisons of misinformation effects in cued recall and recognition memory are useful for examining the role of source memory (e.g., Lindsay \& Johnson, 1989) in misinformation effects.
Experiment 1 included only young adults and was designed to investigate the reliance of misinformation effects on memory for the original information. The remaining experiments included older adults. Results from those experiments show that older adults are often captured by misleading information, similar to "I told you" claims, resulting in dramatic levels of false remembering. We use multinomial models to formally evaluate the processes underlying performance. We find that the performance of young adults in all four experiments can be explained by the same dual-process model as used by Jacoby et al. (2001) to account for cued-recall performance under conditions of PI. Explaining the performance of older adults, however, requires postulation of an additional capture process. We report results from each of the experiments and then, in a separate section, further describe the multinomial models along with their fit to the data from the experiments.

\section{Experiment 1}

The suggestion that misleading information has its effects by altering the memory traces of earlier events (Loftus, 1975, 1979) implies that the presentation of misinformation should reduce one's ability to accurately recollect those earlier events. We performed Experiment 1 to determine whether there are effects of a misleading prime on recollection for young adults. A second goal of Experiment 1 was to examine how differences in memory for the original information influence the magnitude of misinformation effects (cf. Belli et al., 1992). Participants studied under conditions of either full or divided attention. Dividing young adults' attention during study has been found to reduce recollection and produce memory results that are similar to those found for older adults (e.g., Jacoby et al., 2001). Use of the attention manipulation allowed us to examine the effects of a misleading prime when recollection was at two different levels, one of which was very low.

The general procedure was similar to that used by Jacoby (1999). Pairs of related words (e.g., knee bone) were presented for study. In one condition, participants devoted full attention to study. In a second, divided-attention condition, participants studied the word pairs while simultaneously engaged in a listening task that involved monitoring for sequences of three consecutive odd numbers. We tested memory by providing the left-hand member of each pair along with a fragment of the right-hand member (e.g., knee $\left.b \_n \_\right)$as cues for its recall. Immediately prior to the recall test for each pair, a prime word was presented. The prime was either the same as the target word (a valid prime; e.g., bone), an alternative to the target word (an invalid prime; e.g., bend), or a neutral, nonword stimulus (a baseline prime).

The invalid prime condition was meant to be akin to a false "I told you" claim. For that condition, the prime was a plausible alternative to the target word in that, like the target, it was related to the context word and completed the fragment. Unlike in paradigms used to examine misinformation effects (e.g., Loftus, 1975), we made the source of (mis)information obvious by presenting primes immediately prior to the memory tests. The invalid prime and baseline conditions correspond to the experimental and control conditions in a standard investigation of misinformation effects. However, rather than restricting comparison to those conditions, as is traditionally done to investigate misinformation effects, we combined results from the valid and invalid prime conditions to 
estimate the contributions of recollection and accessibility bias to memory performance (cf. Jacoby et al., 2001).

Comparisons with the baseline condition allow us to ask whether the presentation of a prime selectively influenced accessibility bias or also influenced recollection. The materials were selected such that only two words were associatively related to the cue word and completed the word fragment (e.g., knee $b \_n \_$; bone, bend). Because each of the two words served equally often as the target word across formats, accessibility bias in the baseline condition should be equal at .50 for the two alternative responses. Further, if presentation of a prime had no effect on recollection but did influence accessibility bias, then, compared with the baseline condition, the decrease in correct recall produced by presentation of an invalid prime should be offset by an increase in correct recall produced by presentation of a valid prime. That is, the probabilities of correct recall for the valid and invalid prime conditions should be symmetrical around the baseline condition, because a bias toward one of the two alternatives implies a corresponding bias against the other alternative (cf. Ratcliff \& McKoon, 1995). However, it is important to note that such symmetry is to be expected only if participants always respond with one of our two responses, so that the cued-recall test is equivalent to a two-alternative, forced-choice test. Producing a response other than the two that we chose (e.g., band) or failing to respond, particularly for the baseline condition, resulted in a lack of symmetry even if a manipulation only influenced accessibility bias. The occurrence of such other responses was very rare in Experiment 1 but was more common in Experiment 3. The multinomial model that was fit to the results, described in a later section, takes other responses into account (cf. McBride \& Dosher, 1999).

We expected dividing attention during study to selectively influence recollection while leaving accessibility bias unchanged. In contrast, we expected presentation of a prime to produce an opposite dissociation by selectively influencing accessibility bias while leaving recollection unchanged.

\section{Method}

\section{Participants}

Twenty-four undergraduates at McMaster University, Hamilton, Ontario, Canada, participated in the experiment in exchange for credit in an introductory psychology course. Participants were tested individually.

\section{Materials and Design}

Attention at study (full vs. divided) and prime type condition (valid, invalid, or baseline) were manipulated within participants. A pool of 108 three-word sets, including one cue word (e.g., knee) and two associatively related responses (e.g., bone, bend), were selected from norms reported by Jacoby (1996). The two responses in each set contained the same number of letters and could be used to complete the same word fragment (e.g., $\left.b \_n \_\right)$. Six groups of 15 cue words along with their two response words were selected as critical items. The groups of word sets were balanced for word frequencies. Word length was also balanced for cue words $(M=$ $5.08)$ and response words $(M=4.59)$. The probability that participants would complete word fragments with each of the relevant response words when the cue-word-word-fragment pair was new was balanced across groups ( $M=0.34$ for both response words). As well, each group contained roughly equal numbers of fragments missing the first letter $(M=4.67$ words per group). Word set groups were rotated across participants through each of the six combinations of within-subject conditions produced by the manipulation of attention during study and the prime preceding tests. Across formats, each response word served equally often as the target response. This resulted in 12 formats $(2$ study conditions $\times 3$ prime conditions $\times 2$ targets).

A familiarization list of 432 word pairs was made up of 108 cue words (90 critical plus 18 buffers) presented with each response word twice (e.g., knee-bone twice and knee-bend twice). The study list included 108 word pairs, each pair consisting of a cue word and one of its corresponding response words. To avoid primacy and recency effects, 6 buffer items were presented at the beginning and 3 at the end of each of the study lists (full attention and divided attention). Six of the buffer items were later used as practice items for the test. The test list included the 90 critical cue words presented with a word fragment of the response words (e.g., knee- $b \_n \_$). Test items were split evenly into three prime conditions, which resulted in 30 valid prime test items (prime was the same word as presented in the study list), 30 invalid prime test items (prime was the alternative response word to that shown in the study list), and 30 baseline prime test items (prime was $\& \& \& \& \&$ ). In all phases of the experiment, order of presentation was random, with the restriction that no more than three items representing the same condition could be presented in a row.

\section{Procedure}

Stimuli were presented in white, lowercase letters (approximately $3 \times 5$ $\mathrm{mm}$ in size) on a black background in the center of the computer screen. An IBM-compatible computer with a VGA color monitor, along with Micro Experimental Laboratory software (Schneider, 1990), was used to present words and collect responses.

In the familiarization phase, participants were told to read the word pairs out loud at a constant rate. Each word pair remained on the screen for $1.5 \mathrm{~s}$, with a 500-ms interstimulus interval. In the study phase that followed, participants were instructed to read each word pair silently and to remember the pairs for a later memory test. Each study pair was presented for $4.5 \mathrm{~s}$, with a 500-ms interstimulus interval. Half of the study pairs were presented in a divided-attention condition, and the other half were presented in a full-attention condition. The divided-attention study list always preceded the full-attention study list. In the divided-attention condition, participants were told that, in addition to reading the word pairs silently and remembering them for a later test, they were to monitor a list of aurally presented single-digit numbers for three odd numbers in a row. Digits were presented at a rate of one every $1.5 \mathrm{~s}$. Participants were told to press a key on the keyboard when such a sequence was detected. They were instructed that their primary task was to monitor the numbers and that, if possible, they were not to miss any sequences. To let participants get used to the numbers task, we did not begin presentation of the study words until the participant had signaled detection of three odd number sequences. The experimenter pointed out any missed sequences to the participant by saying "missed." In the full-attention condition, participants were told only to read each word pair silently and to remember the pairs for later.

Prior to the test, participants were instructed that before each test pair, a single word (the prime) or a row of ampersands would be presented. They were told to read silently and try to remember the words that served as primes for a later test that was not actually given. Test pairs that were presented were described as being from the list that was studied silently, with some letters missing from the bottom word. Participants were told to use the cue word to help them complete the fragment with the word that was earlier studied in the pair and were warned that, although the single word presented prior to the test pair would fit into the word fragment and would be related to the cue word, it might or might not be the same word as presented in the study list. Participants were instructed to respond aloud to each test item, guessing if necessary, and were told that guesses should complete the fragment with a word that was related to the cue word.

Each test trial began with a 1 -s presentation of two plus signs ( 10 spaces apart) marking the location on the screen where the prime was to appear. 
The prime was presented for $500 \mathrm{~ms}$ and was followed by a 500 -ms blank screen. Following this, the word fragment was presented in the same location as the prime, with the cue word one line above. The cue word and word fragment remained on the screen until the participant made a response or, failing that, until $7 \mathrm{~s}$ had elapsed, after which time the computer proceeded to the next trial. After an intertrial interval of $500 \mathrm{~ms}$, the next trial was presented.

\section{Results and Discussion}

In the divided-attention condition, the probability that the participant would fail to detect a target sequence for the listening task was .07. Probabilities of correct recall (see Table 1) were analyzed in a $2 \times 3$ mixed-models analysis of variance (ANOVA), with attention at study and prime type as within-subject variables. There was a significant main effect of attention condition, $F(1,23)=$ 47.50, MSE $=0.026, p<.001, \eta_{\mathrm{p}}^{2}=.67$, and the main effect of prime condition was also highly significant, $F(2,46)=37.82$, $M S E=0.020, p<.001, \eta_{\mathrm{p}}^{2}=.62$. The interaction was not significant, $F<1$.

In both the full- and the divided-attention conditions, probabilities of correct recall on valid prime and invalid prime test items were nearly perfectly symmetrical around performance on baseline items (see Table 1), which suggests that dividing attention during study reduced recollection but left accessibility bias unchanged, whereas presenting a prime had its effect by influencing accessibility bias while leaving recollection unchanged. Confirming this symmetry, baseline probability correct (.62) was nearly identical to the average probability correct of valid and invalid conditions (.61; $t<1$ ). A multinomial model whose fit confirms this account is presented immediately prior to the General Discussion.

The within-subject manipulation of full versus divided attention was such that the divided-attention condition also had a longer retention interval than did the full-attention condition. We structured the conditions this way to produce a large difference between the two conditions in recollection. The pattern of results is the same as that found for PI (Jacoby et al., 2001). Contrary to trace-alteration accounts of the misinformation effect (e.g., Loftus, 1979), presentation of a misleading prime did not influence recollection. The interference produced by an invalid prime was nearly perfectly offset by the facilitation produced by a valid prime. These results are consistent with McClosky and Zaragoza's (1985) claim that postevent information generally does not impair memory for target events. They also shed new light on findings that misinformation effects are larger when memory for the target event is poor (e.g., Belli et al., 1992) by suggesting that such increased interference can result from greater reliance on guessing, which reflects accessibility bias.

Table 1

Cued-Recall Probability Correct in Experiment 1

\begin{tabular}{|c|c|c|c|c|c|c|}
\hline \multirow[b]{3}{*}{ Attention } & \multicolumn{6}{|c|}{ Prime condition } \\
\hline & \multicolumn{2}{|c|}{ Valid } & \multicolumn{2}{|c|}{ Baseline } & \multicolumn{2}{|c|}{ Invalid } \\
\hline & $M$ & $S D$ & $M$ & $S D$ & $M$ & $S D$ \\
\hline Full & .81 & .10 & .71 & .12 & .59 & .18 \\
\hline Divided & .65 & .14 & .53 & .11 & .38 & .12 \\
\hline
\end{tabular}

\section{Experiment 2}

It is unclear whether the effect of accessibility bias produced by an invalid prime in Experiment 1 should be called false memory. Rather, participants might simply have been guessing and experienced their response as being such. In Experiment 2, subjective reports of memory were required. After completing each fragment, participants reported on the basis for their response by saying "remember," "familiar," or "guess" (cf. Gardiner, 1988; Gardiner \& Richardson-Klavehn, 2000). ${ }^{1}$

Effects of a prime on subjective reports of memory by older adults are important for the example of memory scams used to begin this article. A memory scam that relies on a false "I told you" claim is most successful if the victim of the scam falsely remembers the misleading information as being the original. The probability of correct "remember" responses has been found to be lower for older adults, whether memory is tested by means of a recognition test (e.g., Parkin \& Walter, 1992; Perfect \& Dasgupta, 1997; but see Mark \& Rugg, 1998) or by means of a cued-recall test (Mäntylä, 1993). However, greater false remembering for older adults was found (Norman \& Schacter, 1997) when participants were presented a list of associates to a theme word that was itself not presented (Deese, 1959; Roediger \& McDermott, 1995). Also, Karpel et al. (2001) examined age differences in a misinformation paradigm and found that older adults more often reported false memories, and with greater confidence, than did young adults. In contrast, Jacoby et al. (2001) found that older adults" "remember" responses were almost as likely to be accurate as were those of young adults.

As noted in the introduction, degree of original learning has not been equated in experiments that have found age-related increases in misinformation effects (e.g., G. Cohen \& Faulkner, 1989; Karpel et al., 2001). Results from Experiment 1 show that, for young adults, interference produced by a misleading prime is fully caused by accessibility bias, even when recollection is near zero. These results suggest that, for older adults, any effects of prime presentation that go beyond accessibility bias cannot be due to the adults' low levels of recollection. To further rule out effects of differences in original learning as a cause of age differences in susceptibility to interference, we attempted to equate recollection for young and older adults in Experiment 2 by presenting study items to older adults for a longer duration than that used for young adults. Our choice of presentation rates was aimed at equating the performance of young and older adults on control items, for which a prime was not presented.

On the basis of results from the young adults in Experiment 1, we expected presentation of a prime not to influence the probability of recollection. However, presentation of a prime word might be sufficient to make it a prepotent response for older adults. Older adults might be captured by the prime and thus be less likely to engage in recollection than they would be had a prime not been presented. Such capture would be evidenced by asymmetry of performance in the valid and invalid prime conditions around performance in the baseline condition, with the asymmetry being

\footnotetext{
${ }^{1}$ We used "familiar" instead of "know" because the latter can be confused for its homophone no. The word know also tends to convey certainty in its everyday usage, whereas we wanted high-certainty responses to be reported as "remembered."
} 
such that the interfering effect of an invalid prime is larger than the facilitative effect of a valid prime (see Appendix A for derivation). Perhaps most interesting, getting captured by a prime might make older adults very likely to falsely remember that prime as having been studied earlier.

\section{Method}

\section{Participants}

The young adult group $(n=24)$ ranged in age from 18 to 27 years $(M=$ $20.5, S D=2.06$ ). The young adults were recruited through flyers posted on the Washington University campus and were paid $\$ 10$ for participating in the experiment. The older adult group $(n=24)$ was drawn from the Washington University psychology department older adult participant pool and ranged in age from 64 to 87 years $(M=74.6, S D=5.26)$. The older adults were volunteers from the St. Louis community and were paid $\$ 10$ for participating in the experiment. The mean score on the Vocabulary subtest of the Shipley Institute of Living Scale (Shipley, 1986) was lower for younger participants $(M=33.42, S D=2.62)$ than for older participants $(M=35.96, S D=2.27), t(46)=3.59, p<.005$. The highest educational attainment for the young adults varied from some high school to a master's degree, with the median being some college. The highest educational attainment for the older adults varied from a high school diploma to a master's degree, with the median being a bachelor's degree.

\section{Materials and Design}

The experiment was designed as a mixed factorial, with age as the between-subjects factor and prime type (valid, invalid, baseline) as the within-subject factor. Sixty-nine word sets (cue words along with their two response words) were chosen from those used in Experiment 1. Chosen sets were those that elicited very few null responses in previous experiments. Three groups of 20 sets were selected as critical items. The groups of word sets were balanced for word frequencies of cue words and response words, word length for cue words and response words, probability of completing word fragments with each of the relevant response words when new, and number of fragments missing the first letter. Word set groups were rotated across participants through valid prime, invalid prime, and baseline conditions. Each response word served equally as often as a target response. This resulted in six formats ( 3 test conditions $\times 2$ response groups).

A familiarization phase was not used in Experiment 2, as results from a preliminary experiment suggested that including such a phase produced source confusion at test for older adults. That is, older adults were likely to confuse memory for the familiarization list with memory for the study list. The study list was made up of 60 critical word pairs plus buffer items, six presented at the beginning and three at the end of the list to avoid primacy and recency effects. Six of the buffer items were later used as practice items at test. The study list therefore included 69 word pairs, each pair consisting of a cue word and one of its corresponding response words. The test list included the 60 critical cue words presented with a word fragment of the response words. Twenty of these were valid prime items, 20 were invalid prime items, and 20 were baseline prime items.

\section{Procedure}

Stimuli were presented via the same equipment and software as in Experiment 1 . The only difference in presentation for Experiment 2 was an increase in letter size to accommodate the poorer visual acuity of the older adults. Letters measured approximately $5 \times 8 \mathrm{~mm}$ in size.

Study phase instructions and presentation procedures were the same as in Experiment 1, except that study pairs were presented for $1 \mathrm{~s}$ for young participants and $3 \mathrm{~s}$ for older participants. Test phase instructions and presentation procedures were also the same as in Experiment 1, except that, after participants responded aloud with their completion word, a subjective-report prompt (i.e., "Remember, Familiar, or Guess?") was presented on the screen. Participants were to make "remember" judgments when they recalled specific details of the item's presentation so that they were certain that the item was in the study list. They were to judge items to be "familiar" if they knew that they had studied the item but could not recall specific details about studying it. Finally, they were to make "guess" judgments if they were purely guessing, with no idea of the correct answer. Participants were given up to $15 \mathrm{~s}$ to respond.

\section{Results and Discussion}

We first report analyses of cued-recall performance, ignoring subjective reports, and then report analyses that include subjective reports.

\section{Cued-Recall Performance}

As shown in Table 2, our attempt to equate the performance of young and older adults on baseline trials was successful; the two groups produced identical performance on those trials. However, performance on primed trials differed for the young and older adults. For young adults, the interference produced by invalid primes was perfectly offset by facilitation produced by valid primes; performance in the prime conditions was symmetrical around that in the baseline condition, replicating results from Experiment 1. Baseline probability correct (.70) was identical to the average probability correct of valid and invalid conditions (.70; $t<1$ ). In contrast, the older adults showed a larger effect of the primes than did the young, and performance in the prime conditions was asymmetrical around baseline, such that the reduction in the probability of a correct response produced by an invalid prime was greater than the gain produced by a valid prime. For older adults, baseline probability correct (.70) was significantly higher than the average probability correct of valid and invalid conditions (.62), $t(23)=2.78, p<.05$. Results from a multinomial analysis, presented in a later section, show that the asymmetry for older adults was not simply because of a ceiling effect for performance in the valid prime condition.

A $2 \times 3$ mixed-model ANOVA comparing probabilities of correct recall as a function of age and prime condition revealed a significant main effect of age, $F(1,46)=4.06, M S E=0.025, p<$ $.05, \eta_{\mathrm{p}}^{2}=.08$. The main effect of prime condition was also significant, $F(2,92)=161.47, M S E=0.018, p<.0001, \eta_{\mathrm{p}}^{2}=.78$,

Table 2

Cued-Recall Performance in Experiment 2

\begin{tabular}{|c|c|c|c|c|c|c|}
\hline \multirow[b]{3}{*}{ Group } & \multicolumn{6}{|c|}{ Prime condition } \\
\hline & \multicolumn{2}{|c|}{ Valid } & \multicolumn{2}{|c|}{ Baseline } & \multicolumn{2}{|c|}{ Invalid } \\
\hline & $M$ & $S D$ & $M$ & $S D$ & $M$ & $S D$ \\
\hline \multicolumn{7}{|c|}{ Correct recall } \\
\hline Young & .89 & .10 & .70 & .14 & .51 & .20 \\
\hline Older & .93 & .05 & .70 & .12 & .31 & .19 \\
\hline \multicolumn{7}{|l|}{ False recall } \\
\hline Young & .11 & .09 & .27 & .14 & .48 & .20 \\
\hline Older & .06 & .05 & .27 & .12 & .68 & .20 \\
\hline
\end{tabular}


as was the Age $\times$ Prime interaction, $F(2,92)=11.24, M S E=$ $0.018, p<.0001, \eta_{\mathrm{p}}^{2}=.20$.

\section{Subjective Reports}

For young adults, the probability of a "remember" response was little affected by presentation of a prime (see Table 3), just as would be expected if "remember" responses largely reflect the probability of recollection, which was unchanged by presentation of a prime. In contrast, older adults were much more likely to claim to "remember" than were young adults, and presentation of a prime had a large effect on their "remember" responses. An analysis of correct recall accompanied by a judgment of "remember" revealed a highly significant effect of age, $F(1,46)=15.25$, $M S E=0.08, p<.001, \eta_{\mathrm{p}}^{2}=.25$. The main effect of prime condition was also significant, $F(2,92)=67.99, M S E=0.02, p<$ $.00001, \eta_{\mathrm{p}}^{2}=.60$, as was the Age $\times$ Prime interaction, $F(2,92)=$ $35.45, M S E=0.02, p<.00001, \eta_{\mathrm{p}}^{2}=.44$.

Older adults were dramatically more likely to falsely remember words presented as an invalid prime than were young adults. The probability of falsely recalling an invalid prime and saying "remember" was .04 for young adults and .43 for older adults; the Age $\times$ Prime interaction for false remembering was highly significant, $F(2,92)=35.10, M S E=0.014, p<.0001, \eta_{\mathrm{p}}^{2}=.43$. When "remember" responses were conditionalized on reporting an invalid prime, the higher false remembering by older adults remained (.59 vs. .09).

In sum, the results of Experiment 2 show that older adults were more likely to incorrectly recall an invalid prime that was meant to mimic a misleading "I told you" claim than were young adults. A similar result was reported by Jacoby (1999). We go beyond that earlier article by showing that the difference in recall remains even when the performance of young and older adults is equated on baseline tests and by showing age-related differences in subjective reports. The pattern of results suggests that older adults were sometimes captured by the prime and that, when that happened, their subjective experience was often that of "remembering" the invalid prime as having been studied earlier. Perhaps they were remembering, but remembering the prime rather than the earlier studied word. ${ }^{2}$ In contrast, young adults very rarely falsely remembered in the invalid prime condition. Instead, for young adults, incorrect recall reflected accessibility bias and was most often accompanied by a subjective experience of guessing.

Table 3

Probability of a "Remember" Response in Experiment 2

\begin{tabular}{|c|c|c|c|c|c|c|}
\hline \multirow[b]{3}{*}{ Group } & \multicolumn{6}{|c|}{ Prime condition } \\
\hline & \multicolumn{2}{|c|}{ Valid } & \multicolumn{2}{|c|}{ Baseline } & \multicolumn{2}{|c|}{ Invalid } \\
\hline & $M$ & $S D$ & $M$ & $S D$ & $M$ & $S D$ \\
\hline \multicolumn{7}{|c|}{ Correct recall } \\
\hline Young & .38 & .21 & .36 & .20 & .30 & .21 \\
\hline Older & .77 & .20 & .58 & .19 & .24 & .17 \\
\hline \multicolumn{7}{|l|}{ False recall } \\
\hline Young & .01 & .03 & .04 & .05 & .04 & .04 \\
\hline Older & .03 & .03 & .13 & .10 & .43 & .30 \\
\hline
\end{tabular}

\section{Experiment 3}

The results of Experiment 2 reveal that older adults were more likely to "remember" words presented as primes than were young adults and were dramatically more likely to falsely remember invalid primes. Are older adults also willing to act on their subjective experience by responding even when not forced to do so? Koriat and Goldsmith $(1994,1996)$ examined people's ability to regulate memory accuracy by comparing performance in forcedresponding conditions with that in free-responding conditions under which participants were allowed to withhold responses. When answering memory queries under conditions of free responding, people can choose to withhold nonconfident responses (i.e., "guesses") and thus reduce the probability of false recall. However, if subjective experience is used as a guide for deciding whether to volunteer a response, then the results of Experiment 2 suggest that older adults are much less likely to take advantage of an opportunity not to respond than are young adults.

Experiment 3 compares the performance of young and older adults under conditions of free versus forced responding. For the free-responding condition, participants were instructed not to guess. We expected age differences produced by the free-forced manipulation to accord with those found in Experiment 2 for subjective experience, with older adults being less likely than the young to take advantage of the option to pass in the freeresponding conditions.

\section{Method}

\section{Participants}

The young adult group was made up of 24 Washington University undergraduates, ranging in age from 18 to 19 years $(M=18.4, S D=0.49)$, who participated in exchange for credit in a psychology course. The older adult group ( $n=24$ ) was drawn from the Washington University psychology department older adult participant pool and ranged in age from 65 to 85 years $(M=75.6, S D=5.13)$. The older adults were volunteers from the St. Louis community and were paid $\$ 10$ for participating in the experiment. The mean score on the Vocabulary subtest of the Shipley Institute of Living Scale was lower for young $(M=33.17, S D=2.39)$ than for older participants $(M=35.04, S D=2.26), t(46)=2.80, p<.01$. The highest educational attainment for all of the young adults was some college. The highest educational attainment for the older adults varied from a high school diploma to a master's degree, with the median being a bachelor's degree.

\section{Materials and Design}

The experiment included two within-subject variables: response condition at test (free vs. forced) and prime type (valid, invalid, or baseline). Critical stimuli were from the same pool as was used to select critical stimuli for Experiment 2, but the number of items that were required was

\footnotetext{
${ }^{2}$ One concern with these results is that perhaps a few older adults did not understand the instructions and always produced the prime as a response because they mistakenly believed that they were instructed to do so. In fact, only 1 older adult showed zero probability of correct responding in the invalid prime condition. When this participant's data were excluded from the analysis, all Age $\times$ Prime interactions (on cued-recall correct, "remember" correct, and "remember" incorrect responses) remained significant $(p s<.001)$.
} 
larger, so we were unable to use as stringent a criterion for selecting "good" items-items that elicited very few null responses or responses other than one of the two alternative responses that we chose. The six groups of 15 cue words along with their two response words were rotated across participants through each of three prime conditions. Each response word served equally often as a target response. Items were assigned to a specific testing order, but the order of instructions (free vs. forced) was counterbalanced across participants. This caused assignment of items to either free or forced conditions to vary by participant, resulting in 12 formats ( 3 prime conditions $\times 2$ target responses $\times 2$ instruction orders).

The study list was made up of 99 word pairs, each pair consisting of a cue word and one of its corresponding response words. To avoid primacy and recency effects, we presented nine buffer items, six at the beginning and three at the end of the study list. Six of the buffer items, which were constant for all formats, were later used as practice items at test. The test list included the 90 critical cue words presented with a word fragment of the response words. In all phases of the experiment, order of presentation was random, with the restriction that no more than three items representing the same combination of conditions could be presented in a row.

\section{Procedure}

Study phase instructions and presentation procedures were the same as in Experiment 2. For the forced-response condition, the test instructions were the same as in Experiment 2, except that no subjective report was required. For the free-responding condition, participants were told to respond with a completion word only if they could recall which word was presented in the study list; otherwise, they were instructed not to guess and, instead, to respond "pass."

\section{Results and Discussion}

The design of the experiment was such that, for some participants, the free-responding condition was given prior to the forcedresponding condition, whereas, for other participants, the order of conditions was reversed. Order of conditions did not produce a significant main effect, nor did it reliably interact with any other factor or combination of factors (all $F \mathrm{~s}<1$ ). Consequently, results were collapsed across test order.

Probabilities of correct and false recall as a function of age and prime condition are displayed in Table 4. Results for forced responding were similar to those found in Experiment 2, with the major difference being that older adults were a bit less likely to be correct on baseline tests than were young adults (as compared with the nearly identical performance in Experiment 2). Also, both young and older adults were less likely to produce one of our two alternative responses on baseline trials in Experiment 3 than in Experiment 2. Consequently, one cannot expect the symmetry of prime conditions around the baseline condition that was found for young adults in Experiment 2. The multinomial analysis, reported later, takes the lack of responding in the baseline condition into account when testing whether the effects of the prime were fully due to an influence on accessibility bias.

An analysis of the probability of correct recall revealed a significant main effect of prime condition, $F(2,92)=103.37, M S E=$ $0.045, p<.00001, \eta_{\mathrm{p}}^{2}=.69$, as well as a significant Age $\times$ Prime interaction, $F(2,92)=8.32, M S E=0.045, p<.01, \eta_{\mathrm{p}}^{2}=.15$. As in Experiment 2, older adults were more influenced by the primes than were young adults. There was also a significant main effect of free versus forced responding, $F(1,46)=26.72, M S E=0.017$, $p<.0001, \eta_{\mathrm{p}}^{2}=.37$. No other main or interaction effects on the probability of correct recall were significant, $p \mathrm{~s}>.10$.
Table 4

Correct Recall and False Recall in Experiment 3

\begin{tabular}{|c|c|c|c|c|c|c|}
\hline \multirow[b]{3}{*}{ Group } & \multicolumn{6}{|c|}{ Prime condition } \\
\hline & \multicolumn{2}{|c|}{ Valid } & \multicolumn{2}{|c|}{ Baseline } & \multicolumn{2}{|c|}{ Invalid } \\
\hline & $M$ & $S D$ & $M$ & $S D$ & $M$ & $S D$ \\
\hline \multicolumn{7}{|c|}{ Correct recall } \\
\hline \multicolumn{7}{|l|}{ Young } \\
\hline Forced & .85 & .12 & .71 & .13 & .49 & .22 \\
\hline Free & .70 & .16 & .60 & .12 & .43 & .20 \\
\hline \multicolumn{7}{|l|}{ Older } \\
\hline Forced & .89 & .15 & .66 & .17 & .33 & .27 \\
\hline Free & .85 & .11 & .58 & .13 & .28 & .24 \\
\hline
\end{tabular}

False recall

\begin{tabular}{lllllll} 
Young & & & & & & \\
$\quad$ Forced & .14 & .10 & .20 & .09 & .48 & .22 \\
$\quad$ Free & .08 & .08 & .15 & .10 & .28 & .25 \\
Older & & & & & & \\
$\quad$ Forced & .07 & .10 & .22 & .12 & .62 & .31 \\
Free & .06 & .06 & .22 & .13 & .59 & .29 \\
\hline
\end{tabular}

An analysis of "pass" responses (see Table 5) showed that young adults were more likely to pass in the free-responding condition than were older adults (.25 vs. .11), $F(1,46)=21.79$, $M S E=0.029, p<.0001, \eta_{\mathrm{p}}^{2}=.32$. There was also a main effect of prime, $F(2,92)=3.49, M S E=0.013, p<.05, \eta_{\mathrm{p}}^{2}=.07$. The Age $\times$ Prime interaction was not significant, $F(2,92)=2.06, p>.10$.

Of greatest interest was the reduction in false recall that was achieved when participants were allowed to say "pass" rather than respond. As in Experiment 2, older adults were more likely to falsely recall an invalid prime than were young adults when recall was forced. When given the option to pass (free-responding condition), young participants were more likely to pass in the invalid prime condition than were older participants (.28 vs. .11). By not responding, young adults greatly reduced their probability of falsely recalling invalid primes, as compared with the condition in which responding was forced (.28 vs. .48). For the older adults, in contrast, false recall of invalid primes was nearly identical for the free- and forced-responding conditions (.59 vs. .62). An analysis of false recall in the invalid prime condition revealed a significant interaction between age group and free versus forced responding, $F(1,46)=9.39, M S E=0.017, p<.01, \eta_{\mathrm{p}}^{2}=.29$. The dramatic age difference in false recall of invalid primes agrees with the finding in Experiment 2 that older adults were much more likely to falsely remember invalid primes.

In sum, the manipulation of forced versus free responding produced age differences that are in accord with those found for subjective experience in Experiment 2. Older adults in Experiment 2 were less likely to report their responses as originating from a guess than were young adults and, when told not to guess in the free-responding condition of Experiment 3, were less likely to take advantage of the option to pass than were young adults.

\section{Experiment 4}

One account for the high degree of false remembering shown by older adults is that they are sometimes captured by the prime. By 
Table 5

Probability of Passing in Experiment 3

\begin{tabular}{|c|c|c|c|c|c|c|}
\hline \multirow[b]{3}{*}{ Age group } & \multicolumn{6}{|c|}{ Prime condition } \\
\hline & \multicolumn{2}{|c|}{ Valid } & \multicolumn{2}{|c|}{ Baseline } & \multicolumn{2}{|c|}{ Invalid } \\
\hline & $M$ & $S D$ & $M$ & $S D$ & $M$ & $S D$ \\
\hline Young & .22 & .16 & .24 & .14 & .28 & .17 \\
\hline Older & .07 & .10 & .16 & .10 & .11 & .12 \\
\hline
\end{tabular}

that account, the problem is one of attention. Older adults are less likely to inhibit the prepotent response that is produced by presentation of a prime (cf. Hasher \& Zacks, 1988) or are more likely to neglect the goal of recollecting an earlier studied word (cf. Duncan et al., 1996) than are young adults. The inhibition-deficit and the goal-neglect accounts both hold that the deficit shown by older adults is one of attention that results in the earlier studied word not being brought to mind. In contrast, source memory accounts of the misinformation effect hold that it originates from confusion regarding the source of the misleading information (e.g., Lindsay, 1993). Older adults are much poorer at reporting the source of memories than are young adults (e.g., Spencer \& Raz, 1995) and might fail to use source memory to edit their responses. By a source memory account, the high degree of false remembering shown by older adults arises from a deficit in an editing process that operates after an item comes to mind. In contrast, Jacoby, Kelley, and McElree (1999) distinguished among processes that bring a potential response to mind, early selection processes, and editing processes that can involve source memory and serve as a means of late correction. They argued that differences in early selection processes are often responsible for agerelated differences in memory.

Techniques used to assess source memory (e.g., Johnson, Hashtroudi, \& Lindsay, 1993; Mitchell \& Johnson, 2000) are similar to those used to examine list differentiation in investigations inspired by classic interference theory (e.g., Winograd, 1968). In these investigations, a person's ability to identify a response as coming from List 1 or List 2 was said to be important in overcoming response competition. Age declines in source memory (e.g., McIntyre \& Craik, 1987) may result in poorer list discrimination and be responsible for older adults' increased susceptibility to interference. However, commenting on the role of list differentiation, Postman and Underwood (1973) said that "the critical factor is not the subject's ability to identify the list membership of whatever responses do occur but rather the mechanism governing the availability of alternative response repertoires for recall" (p. 24). Similarly, our capture model holds that differences in bringing an item to mind are critical for understanding age differences in false remembering. We argue that young adults specify retrieval cues in a way that restricts retrieval to earlier studied words and thereby controls what comes to mind. In contrast, because of a deficit in cue specification (cf. Burgess \& Shallice, 1996), older adults' retrieval is poorly constrained, with the result that they are sometimes captured by a prime.

Experiment 4 used the same design as used in Experiment 2, except that we tested recognition memory rather than cued recall. The question was whether the high false remembering found for older adults on a cued-recall test would also be found for recognition memory. Age differences in memory performance are generally smaller for recognition memory than for recall tests (e.g., Craik \& Jennings, 1992), as is RI (e.g., Postman \& Stark, 1969). However, if source identification is the critical factor, older adults would be expected to show high false remembering on a test of recognition memory. This assumes that source identification has its effect by means of an editing process that operates after an item comes to mind and that it does not matter whether an item is brought to mind by means of retrieval or by being presented on a recognition-memory test. By a capture account, in contrast, it matters how an item is brought to mind, so differences in false remembering for cued-recall and recognition-memory tests are to be expected. Older adults might avoid capture and not show dramatically high false remembering if alternative responses are provided for a recognition-memory test.

\section{Method}

\section{Participants}

The young adult group was made up of 24 Washington University undergraduates, ranging in age from 17 to 20 years $(M=18.5, S D=0.8)$, who participated in exchange for credit in an undergraduate psychology course. The older adult group $(n=24)$ was drawn from the Washington University psychology department older adult participant pool and ranged in age from 64 to 84 years $(M=74.3, S D=5.8)$. Because of experimenter error, Shipley Vocabulary scores and education levels were not collected for participants in Experiment 4. However, these participants were drawn from the same populations as participants in Experiments 2 and 3, so it seems likely that their Shipley scores and their highest educational attainment would be similar to those found in the earlier experiments.

\section{Materials, Design, and Procedure}

Materials, design, and procedure were identical to those in Experiment 2, with one exception: After presentation of the prime word, instead of the cue word and fragment, participants were presented with two pairs of words (e.g., knee bone and knee bend) on the same line, approximately 10 spaces apart. Participants were to choose the pair that had been in the study list. After responding aloud with their recognition decision, they were asked to judge whether the chosen pair was "remembered," "familiar," or just a "guess."

\section{Results and Discussion}

As shown in Table 6, the use of a longer study duration for older adults resulted in the recognition-memory performance of young and older adults being equated for baseline tests. In contrast to cued-recall performance (Experiments 2 and 3), young adults showed almost no effect of a prime on their recognition-memory

Table 6

Forced-Choice Probability Correct in Experiment 4

\begin{tabular}{|c|c|c|c|c|c|c|}
\hline \multirow[b]{3}{*}{ Age } & \multicolumn{6}{|c|}{ Prime condition } \\
\hline & \multicolumn{2}{|c|}{ Valid } & \multicolumn{2}{|c|}{ Baseline } & \multicolumn{2}{|c|}{ Invalid } \\
\hline & $M$ & $S D$ & $M$ & $S D$ & $M$ & $S D$ \\
\hline Young & .78 & .13 & .80 & .11 & .79 & .13 \\
\hline Older & .86 & .10 & .78 & .11 & .68 & .16 \\
\hline
\end{tabular}


judgments. Older adults showed a smaller effect of the prime in recognition-memory than in cued-recall performance (cf. Tables 6 and 2). There was a significant main effect of prime, $F(2,92)=$ $6.45, M S E=0.012, p<.01, \eta_{\mathrm{p}}^{2}=.12$, as well as a significant interaction between age and prime, $F(2,92)=9.63, p<.001, \eta_{\mathrm{p}}^{2}$ $=.17$. When age groups were analyzed separately, the main effect of prime was significant for older adults, $F(2,46)=14.90, p<$ $.0001, \eta_{\mathrm{p}}^{2}=.39$, but not for young adults, $F<1$.

\section{Subjective Experience}

An analysis of correct recall for items judged to be "remembered" (see Table 7) revealed a significant main effect of prime, $F(2,92)=5.13, M S E=0.012, p<.01, \eta_{\mathrm{p}}^{2}=.10$, as well as a significant interaction of age and prime, $F(2,92)=8.10, M S E=$ $0.012, p<.001, \eta_{\mathrm{p}}^{2}=.15$. For young adults, correct remembering was not influenced by presentation of a prime, as would be expected if their "remembering" primarily reflected recollection. In contrast, older adults were less likely to correctly remember in the invalid prime condition than in the other conditions. The main effect of prime on correct remembering was significant in older adults, $F(2,46)=12.15, p<.0001, \eta_{\mathrm{p}}^{2}=.35$, but not young adults, $F<1$.

Of greatest interest, there were age differences in false remembering. As found for cued recall, young adults were less likely to falsely remember an invalid prime than were older adults (.02 vs. .09). The interaction of age and prime condition was significant, $F(2,92)=5.67, M S E=0.003, p<.01, \eta_{\mathrm{p}}^{2}=.11$. However, the false remembering by older adults on the recognition-memory test (.09) was much less dramatic than that found in cued-recall performance in Experiment 2 (.43).

In sum, the results show an age difference in susceptibility to interference on a test of recognition-memory performance that cannot be explained as being produced by a difference in original learning. Performance was equated for young and older adults on baseline tests. It is also important to note that comparisons of recognition-memory results with cued-recall results from Experiment 2 show that the means by which an item is brought to mind is critical both for the probability of a correct response and for subjective experience. Use of a recognition-memory test greatly reduced age differences in susceptibility to interference, particularly the age difference in false remembering.

Table 7

Probability of "Remember" Responses in Experiment 4

\begin{tabular}{|c|c|c|c|c|c|c|}
\hline \multirow[b]{3}{*}{ Age } & \multicolumn{6}{|c|}{ Prime condition } \\
\hline & \multicolumn{2}{|c|}{ Valid } & \multicolumn{2}{|c|}{ Baseline } & \multicolumn{2}{|c|}{ Invalid } \\
\hline & $M$ & $S D$ & $M$ & $S D$ & $M$ & $S D$ \\
\hline \multicolumn{7}{|c|}{ Correct recall } \\
\hline Young & .44 & .17 & .44 & .20 & .46 & .18 \\
\hline Older & .54 & .15 & .50 & .17 & .39 & .15 \\
\hline \multicolumn{7}{|c|}{ False recall } \\
\hline Young & .02 & .04 & .02 & .04 & .02 & .03 \\
\hline Older & .02 & .04 & .05 & .07 & .09 & .11 \\
\hline
\end{tabular}

\section{Multinomial Models of Performance: Overview and Summary}

The experiments we have presented were designed to shed new light on the nature of mnemonic interference by relating such interference to the distinction between controlled and automatic uses of memory and by examining the effects of interference on subjective experience (Experiments 2 and 4 ) and the willingness to respond (Experiment 3 ). The experiments were also designed to explore age-related differences in susceptibility to interference. For this latter goal, a number of findings - of which the most notable is the asymmetry in older adults' performance in the valid and invalid prime conditions as well as their high levels of false remembering-suggest important differences in how young and older adults performed the current tasks. Whereas young adults' performance can be parsimoniously explained in terms of the distinction between recollection and accessibility bias, explaining older adults' performance may require postulation of an additional capture process (cf. Kramer, Hahn, Irwin, \& Theeuwes, 1999; Pratt $\&$ Bellomo, 1999). The purpose of this section is to examine that possibility more formally using multinomial models of performance.

Details of the modeling are provided in the following sections. In summary, we found that the RA model-previously used to account for the performance of both young and older adults in a PI task (Jacoby et al., 2001) — did a good job of accounting for the performance of the young adults in all of the current (i.e., "I told you") experiments. We also found that an expanded version of the RA model that included an attribution threshold parameter provided a good account of the young adults' subjective experience judgments (Experiments 2 and 4) and their performance under conditions of free versus forced responding (Experiment 3). In contrast, the RA model did not provide an acceptable account of the data when the performance of young adults and that of older adults were considered together. Data from the two age groups could be fit, however, with the addition of a capture parameter to the front end of the RA model (see Figure 2). Furthermore, with only one exception (recognition performance in Experiment 4), an expanded version of the capture model that included an attribution threshold parameter was found to provide a good account of the young and older adults' subjective experience and free- versus forced-response data.

\section{Rationale and Method}

Multinomial models permit the testing of specific theories of underlying cognitive operations in a way that traditional approaches, such as ANOVA, cannot (Riefer \& Batchelder, 1988). One reason for this is that multinomial models allow for the possibility of multiple process pathways or branches leading to the same response category. For example, consider a case in which a participant gives a correct response on a valid prime trial. One possibility is that the response was recollected from the earlier studied list. Another possibility is that recollection failed, but the correct response was still given because the prime created an accessibility bias for that word. Multinomial models can help to disentangle underlying processes in such situations. In multinomial models, separate parameters represent the probabilities with which separate processes occur. Processes have a branching pattern, whereby the outcome of processes at various steps determines which branch is followed and, eventually, which category of response is given (for a review, see Batchelder \& Riefer, 1999). 


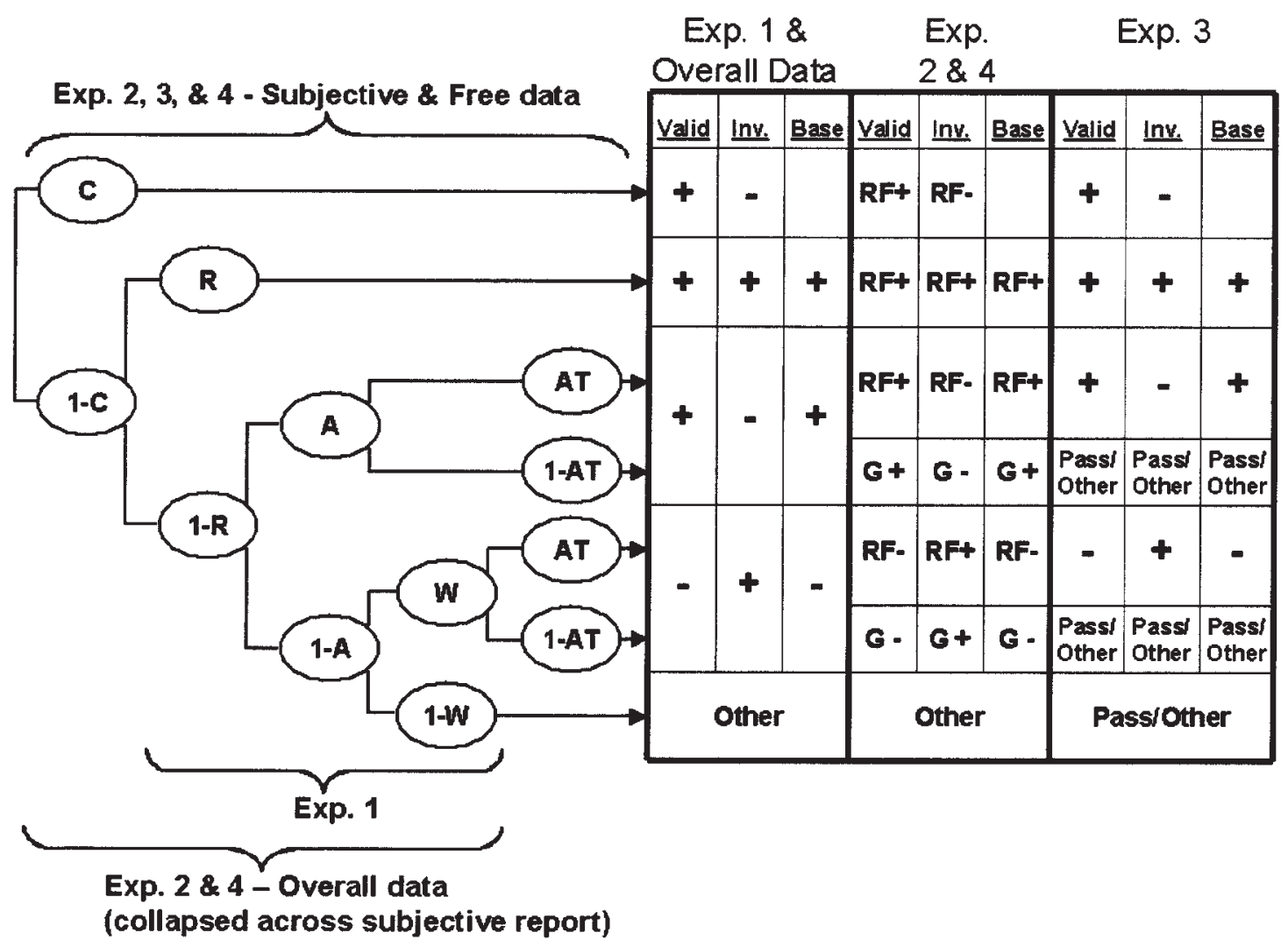

Figure 2. The complete multinomial model, with capture (C), recollection (R), accessibility bias (A), word generation (W), and attribution threshold (AT) parameters. Branches lead to correct recall (+); false recall (-); other responses, including running out of time (other); and passes as well as subjective reports ( $\mathrm{RF}=$ "remember" or "familiar," G = "guess"). Exp. = Experiment; Inv = invalid.

Figure 2 provides a detailed depiction of the processes in the capture model, the model that was used to characterize performance in all four experiments. In this model, capture by the prime (which occurs with probability $C$ ) leads to a correct response (+) on valid prime trials and an incorrect response $(-)$ on invalid prime trials. For subjective-report data (Experiments 2 and 4), capture leads the participant to report the prime as "remembered" or "familiar" rather than as a "guess." When not captured $(1-C)$, successful recollection (with probability $R$ ) leads to correct responding and subjective reports of "remember" or "familiar." Note that the RA model can be viewed as a subset of the capture model when $C$ is set to zero. When both capture and recollection fail to occur, responding may reflect accessibility of the prime (with probability $A$ ). In this case, subjective reports that the prime is "remember" or "familiar" are given only when an attribution threshold is exceeded (with probability AT). When the prime is not accessible $(1-A)$, participants may respond with the alternative response word, but only if they can generate that word (with probability $W)$. When unable to generate the alternative $(1-W)$, participants give a nontarget response or no response. "Remember" and "familiar" responses are grouped together in the model to facilitate the comparison of results with those from Experiment 3. The model predicts that participants will pass in Experiment 3 in situations in which they would have given a "guess" or a response other than the two intended completions.

Multinomial analyses were performed with the Microsoft Excel Solver function (Dodson, Prinzmetal, \& Shimamura, 1998). Solver was used to determine goodness-of-fit values, $G^{2}$, which were then compared with a chi-square distribution with alpha set at .01 . Post hoc analyses using
GPOWER software (Erdfelder, Faul, \& Buchner, 1996) revealed that power always exceeded .999 for detection of medium effect sizes of $w=$ .3 (J. Cohen, 1977). Multinomial models are said to fit the data when $G^{2}$ is below the critical value derived from the chi-square distribution.

To test for a significant difference between two parameter estimates, we compared the fitted model with a nested model that constrained the two parameters of interest to be equal. Similarly, to test for a significant difference between a parameter estimate and a fixed value, the nested model constrained the parameter of interest to that value. The difference in $G^{2}$ between the fitted and nested models was tested against a chi-square distribution with one degree of freedom. We report significance levels for nested model comparisons to distinguish them from general model fitting.

\section{Results and Discussion}

In the following sections, we first examine model fits for young adults' data only, followed by fits of the young and older adults' data considered together. We do this to show that the RA model fits the results from all experiments for young adults. The fact that it does so allows that simple model to serve as a backdrop against which age differences in memory can be assessed.

\section{Young Adults}

Experiment 1. The goal of Experiment 1 was to determine whether differences in recollection (original learning) affect sus- 
ceptibility to interference. On the basis of previous research (e.g., Jacoby et al., 2001), we predicted that dividing the attention of young adults at study would decrease recollection $(R)$ - thereby increasing susceptibility to interference-but have no effect on accessibility bias $(A)$. Conversely, we expected that presentation of a biasing (i.e., "I told you") prime would increase accessibility bias (relative to baseline) but have no effect on recollection. Our predictions would be supported if we found a satisfactory fit of the data when $A$ was constrained to be constant across the manipulation of attention and $R$ was constrained to be constant across prime conditions. In fact, the symmetry of performance in the prime conditions around the baseline condition suggests that presentation of a prime influenced accessibility bias but left recollection unchanged. To further examine the results, we fit the RA model (i.e., Figure 2, with $C$ set to zero) to the data. For that fit, $A$ was set at .50 for the baseline test conditions on the assumption that, for guessing, neither of the two responses would be favored. For the prime conditions (valid vs. invalid), $A$ was allowed to differ from .50 to reflect the influence of the prime but was constrained to be constant across the manipulation of full versus divided attention. In contrast, $R$ was constrained to be constant across the prime conditions but was allowed to vary with the manipulation of full versus divided attention. Participants were slightly less likely to produce one of our intended responses on baseline trials as compared with primed trials (.988 vs. .998). To take that difference into account, we allowed $W$ to differ for the prime and baseline conditions.

The cued-recall results were well fit by this model, with $G^{2}(7)=$ 3.04, far below the critical value of 18.48. Consideration of nested models revealed that full attention during study produced a significantly higher $R$ than did divided attention (.41 vs. .04), $G^{2}(1)=$ $80.14, p<.00001$, and presentation of a prime produced a higher level of $A$ than that in the baseline condition (.65 vs. .50), $G^{2}(1)=$ 92.72, $p<.00001$. Even when allowed to vary, $A$ in the primed conditions did not significantly differ across full (.68) and divided attention (.64), $G^{2}(1)=1.62, p=.20$. Participants were very likely to produce one of the two alternatives that we chose for each item but were slightly more likely to do so in the primed conditions than in the baseline condition ( $W=.98$ vs. .93), $G^{2}(1)=9.71, p<$ .01 . This difference is to be expected, because presentation of a prime made one of our responses highly accessible.

Experiment 2. In Experiment 2, we compared interference effects in young and older adults, in terms of both objective performance (i.e., cued-recall responses) and subjective experience ("remember," "familiar," and "guess" judgments; see Appendix B for the complete data set). The cued-recall results for young adults (collapsed across subjective report) were fit well by the RA model $(C=0), G^{2}(3)=2.29$, critical $=11.34$. Unlike Experiment 1 , the model used only one $R$ parameter and one $W$ parameter. The subjective report data were well fit by the addition of an attribution threshold parameter $(A T)$ to the RA model, $G^{2}(8)=14.03$, critical $=20.09$. The estimated value of $A$ in primed conditions (.79) was higher than $.50, G^{2}(1)=166.42, p<.00001$. Estimated values of the remaining parameters were $R=.40, W=.92$, and $A T=.54$.

It should be noted that we also considered and rejected a model in which the prime's influence came purely through capture rather than accessibility bias. In this case, we allowed $C$ to vary freely and constrained $A$ to .50 in all conditions, which made the model nearly identical to the Stroop model of Lindsay and Jacoby (1994). This model failed to fit both the cued-recall and the subjectivereport data, $G^{2}(3)=21.64$, critical $=11.34$, and $G^{2}(8)=140.18$, critical $=20.09$, respectively. Similarly, Jacoby et al. (2001) found that the RA model was superior to the Stroop model in accounting for cued recall in a proactive interference situation.

Experiment 3. The goal of Experiment 3 was to examine interference effects when participants were allowed to withhold responses (free responding) compared with when they were forced to respond (forced responding). Performance in both of these conditions was analyzed with a model that was identical to that used for subjective reports in Experiment 2, except that a pass in the free-response conditions was treated as analogous to a "guess." The model provided an acceptable fit to the young adults' data, $G^{2}(8)=17.81$, critical $=20.09$. The estimated value of $A$ in primed conditions (.76) was higher than $.50, G^{2}(1)=140.14, p<$ .00001 . The $A T$ parameter was fixed at 1.00 for the forcedresponding condition and estimated to be .63 for the freeresponding condition. Estimated values of the remaining parameters were $R=.39, W=.78$, and $A T=.63$. Note that generation of an alternative word $(W)$ was less probable here than in Experiment 2, which accounts for the lack of symmetry in young adults' performance in Experiment 3.

Experiment 4. Experiment 4 was identical to Experiment 2, except that the test was two-alternative forced choice recognition rather than cued recall (see Appendix B for the complete data set). $W$ was set to 1.00 because both completion words were provided. Results collapsed across subjective report were well fit by the RA model, $G^{2}(1)=0.76$, critical $=6.63$. Subjective-report data were well fit by the addition of an $A T$ parameter to the model, $G^{2}(6)=$ 8.46 , critical $=16.81$. The estimated value of $A$ in the primed conditions (.48) was not significantly different from $.50, G^{2}(1)=$ $0.55, p=.46$, which indicates that the prime had a negligible impact on recognition memory. Estimated values of the remaining parameters were $R=.55$ and $A T=.45$.

\section{Combined Young and Older Adults}

We sought the simplest model that would fit the combined results of both age groups, and we constrained parameters to be the same for young and older adults whenever possible. Of primary interest were situations in which this was not possible, particularly when a difference in the $C$ parameter across age became apparent. These situations suggest that older adults are more likely to be captured by the prime.

Experiment 2. Despite the success of the RA model in fitting young adults' data, the model was not successful when the performance of both young and older adults was considered together. For the cued-recall data (collapsed across subjective report), an RA model with three parameters $(R, A$, and $W$ ) failed to fit, with $G^{2}(9)=53.23$, well above the critical value of 21.67. Because older adults were more affected by the prime than young adults, we considered a four-parameter model in which $A$ was allowed to vary separately for the two age groups. This model also failed to produce an acceptable fit, $G^{2}(8)=29.08$, critical $=20.09$.

The capture model, in contrast, provided a much better fit of the results from both the young and the older adults, $G^{2}(7)=4.50$, critical value $=18.48$. The model had five parameters: two $C \mathrm{~s}$ (one for each age group), one $R$, one $A$, and one $W$. The fit was 
parsimonious in that only the probability of capture by the prime differentiated young and older adults. The estimated value of $C$ was .38 for older adults, which was reliably higher than the value of .00 for young adults, $G^{2}(1)=45.63, p<.00001$. For both the young and the older adults, estimated values of the remaining parameters were $R=.40, A=.81$, and $W=.91$. Even when $R, A$, and $W$ were allowed to vary by age group, they did not differ significantly across age (all $p$ s $>.20$ ).

As with the cued recall data, we first attempted to model the subjective-report data of both young and older adults using the $A T$-expanded version of the RA model. This model had five parameters: $R, A, W$, and two $A T$ parameters, one for each age group. The model provided a poor fit to the data, $G^{2}(19)=99.18$, critical $=36.19$. It also failed to provide an acceptable fit when $A$ was also allowed to vary by age group, $G^{2}(18)=73.26$, critical $=$ 34.81 .

In contrast to the RA model, the capture model (along with $A T$ parameters) provided an acceptable fit to the subjective-report data, $G^{2}(17)=30.28$, critical $=33.41$. As shown in Table 8 , this model fit the data, with only two parameters differing for young and older adults. First, older adults were more likely to be captured by the prime, $G^{2}(1)=65.51, p<.00001$. Second, older adults used a more lenient criterion (a higher value of $A T$ ) for saying "remember" or "familiar" than did young adults, $G^{2}(1)=88.58$, $p<.00001$. That is, older adults were less likely to report experiencing their responses as "guesses."

One might argue that the failure of the RA model for older adults resulted simply from the near ceiling performance of older adults in the valid prime condition. Further analysis ruled out this interpretation. Even when data from the valid prime condition were excluded from analyses, leaving data from the baseline and invalid prime conditions, which were well below ceiling, the RA model failed to fit either the cued-recall or the subjective report data for older adults, $G^{2}(5)=42.86$, critical $=15.09$, and $G^{2}(11)=68.74$, critical $=24.73$, respectively. In contrast, for the baseline and invalid prime conditions, the capture model still fit both the cued-recall and the subjective-report data, $G^{2}(3)=1.37$, critical $=11.34$, and $G^{2}(9)=16.83$, critical $=21.67$. The capture model still estimated values of $C$ to be .00 for young adults when

Table 8

Multinomial Model Parameters

\begin{tabular}{lcc}
\hline Parameter & Experiment 2 & Experiment 3 \\
\hline Cy & .00 & .00 \\
Co & .38 & .24 \\
R & .40 & .39 \\
Ry & & .30 \\
Ro & .79 & .77 \\
A & .91 & .78 \\
W & & .63 \\
Wy & .51 & .63 \\
Wo & .79 & .87 \\
ATy & & \\
ATo & & \\
\hline
\end{tabular}

Note. $\mathrm{Cy}=$ capture, young; $\mathrm{Co}=$ capture, older; $\mathrm{R}=$ recollection; $\mathrm{Ry}=$ recollection, young; Ro = recollection, older; $\mathrm{A}=$ accessibility bias; $\mathrm{W}=$ word generation; $\mathrm{Wy}=$ word generation, young; Wo = word generation, older; $\mathrm{ATy}=$ attribution threshold, young; ATo = attribution threshold, older. data from the valid prime condition were excluded from the analyses. When we compared other parameters, the largest difference between a parameter value obtained from the restricted data set (valid prime condition excluded) and its corresponding parameter value obtained from the complete data set (see Table 8) was .03. Excluding data from the condition that produced ceiling effects for older adults did not substantially change the outcome of analyses, which shows that ceiling effects were not responsible for the failure of the RA model to fit the results for older adults.

Experiment 3. The simplest capture model that fit the data in Experiment 3 required nine free parameters: two parameters (one for each age group) for $C, R, W$, and $A T$, and one $A$ parameter that was constrained to be the same across age. $A T$ was set to 1.00 in the forced-responding condition but allowed to vary in the freeresponding condition. This model provided an acceptable fit, $G^{2}(15)=25.14$, critical $=30.58$.

Examining the parameter values (see Table 8) shows that older adults were more likely to be captured by the prime than young adults (.24 vs. .00), $G^{2}(1)=13.27, p<.001$. Young adults had a higher $R$ than did older adults (.39 vs. .30). Young adults were better able to produce one of the two alternatives that we chose for each item than were older adults ( $W=.78$ vs. .63), $G^{2}(1)=12.04$, $p<.00$, and used a more stringent criterion for responding in the free-response condition than did older adults $(A T=.63$ vs. .87$)$, $G^{2}(1)=33.17, p<.00001$. Even when $A$ was allowed to vary, it did not significantly differ between young (.75) and older adults (.80), $G^{2}(1)=0.67, p=.41$.

Examining parameter values from the model for Experiments 2 and 3 reveals consistencies across the experiments, along with some differences. Accessibility bias was the same across the two experiments, as was the probability of recollection for young adults. However, recollection for older adults was lower in Experiment 3 than in Experiment 2, as was the capture parameter. These differences might have reflected changes in materials across the two experiments, as Experiment 3 had more failures to respond and more production of nontarget responses (i.e., words other than our two chosen alternatives), particularly for older adults. Both young and older adults had lower values of $A T$ in Experiment 3 than in Experiment 2. However, across the two experiments, older adults used a more lenient attribution threshold than did young adults.

Experiment 4. The capture model was applied to the forcedchoice data (collapsed across subjective report) from both young and older adults. $W$ was set to 1.00 because both completion words were provided. It was possible to constrain $R$ and $A$ to be the same for young and older adults, which led to a simple model with four free parameters (two $C$ s, one $R$, and one $A$ ). This model fit the data well, $G^{2}(2)=6.37$, critical $=9.21$. The estimated value of $C$ was greater for older (.16) than young adults (.00), $G^{2}(1)=21.65, p<$ .00001 . For $R$ and $A$, the estimated values were .59 and .50 , respectively.

Although the data were fit well by the capture model, the RA model also fit the forced-choice data. For this RA model, the $C$ parameter was set to zero for both young and older adults, $A$ was allowed to differ for young and older adults, and $R$ was constrained to be equal for the two age groups. With three free parameters (one $R$ and two $A \mathrm{~s}$ ), this model provided a very good fit of the data, $G^{2}(3)=2.08$, critical $=11.34$. The $A$ parameter for young adults (.48) was not significantly different from the level at which it was 
set for baseline tests (.50), $G^{2}(1)=0.50, p=.48$, but $A$ was higher for older adults (.70), $G^{2}(1)=43.12, p<.00001$.

Given that both the RA and the capture models fit the forcedchoice data, it is unclear whether older adults were more likely than young adults to be captured by the prime or, instead, simply had higher accessibility bias. It is difficult to mathematically distinguish the capture and RA models when either the probability of capture or the probability of recollection is low (see Appendix A for further discussion). The choice between models is of concern only for describing the results from older adults. The two models are the same for young adults, as, for them, the capture parameter was estimated to be less than .01 in every experiment. Note that, if one adopts the capture model for older adults, the probability of capture on the recognition test is less than half the probability of capture on the cued-recall test of Experiment 2 (.16 vs. .38). This suggests that, at the very least, capture by a prime is greatly reduced on a test of recognition memory, and it may even be fully eliminated, leaving only an influence of the prime on accessibility bias.

For the subjective reports, it was not possible to adequately fit both the young and the older adults' data by adding an AT parameter to the capture model. This was true even when we fit the model separately for older adults, allowing all parameters in the model to hold a value different from those of the young adults, $G^{2}(6)=44.97$, critical $=16.81$. One possible explanation for this failure to fit is that the forced-choice response format may encourage participants to make subjective reports by comparing the accessibility of the two responses (cf. Bodner \& Lindsay, 2003). This would violate the assumed independence between the $A$ and $A T$ parameters, making model fits unlikely whenever $A$ exceeded .50 (as it did for older but not young adults).

In summary, Experiments 2 and 3 suggest that young adults were not captured by the prime, older adults were sometimes captured by the prime, and accessibility bias was unaffected by age. The forced-choice recognition data from Experiment 4, in contrast, could not distinguish between age effects on capture and age effects on accessibility bias, most likely because the prime had such little impact on recognition memory performance.

\section{General Discussion}

For young adults, the effects on cued-recall performance of presenting a prime meant to mimic an "I told you" claim allow a simple description that is fully in accord with effects found for PI (Hay \& Jacoby, 1996, 1999; Jacoby et al., 2001). Dividing attention during study reduced recollection but did not influence accessibility bias. In contrast, presentation of a prime influenced accessibility bias but did not influence the ability to recollect the original information. When unable to recollect, young adults produced the response that was most accessible, and accessibility was influenced by the prime. As found by Jacoby et al. (2001) for PI, young adults' subjective experience was well calibrated: The probability of a "remember" response was little influenced by presentation of a prime, and false remembering of an invalid prime was rare. When given an option to pass under free-responding conditions, young adults greatly reduced their false recall of invalid primes. Effects of presenting a prime were fully eliminated when a recognition-memory test was given, which shows the importance of generating a response for effects on accessibility bias.
This simple pattern of results for young adults is useful as a backdrop against which to examine age-related differences in susceptibility to interference. The greater susceptibility to interference shown by older, as compared with young, adults was not because of an age difference in original learning (cf. Craik, 1977; Kausler, 1991). Performance on baseline tests was equated for young and older adults, and results from Experiments 2 and 4 were well fit by a model that constrained recollection to be the same across conditions. Rather, older adults were sometimes captured by the prime, producing the prime as a response without attempting recollection. Such capture by the prime was often accompanied by the subjective experience of remembering. Older adults were generally more willing to say "remember" than were young adults, and they showed dramatically higher false remembering of invalid primes. Unlike young adults, older adults did not reduce their false recall when given the option to pass, which is consistent with their high level of false remembering. For older adults, the effects of prime presentation on recognition-memory performance were smaller than found for cued-recall performance but were not fully eliminated. False remembering of invalid primes was much less dramatic for recognition-memory performance than for cued-recall performance, which, again, shows the importance of generating a response for false remembering.

To account for age differences in PI, Jacoby et al. (2001) found it was unnecessary to postulate that older adults suffer an inhibition deficit (e.g., Hasher \& Zacks, 1988) or goal neglect (e.g., Duncan, 1995; Duncan et al., 1996), deficits that would be represented by the capture parameter in the model presented here. Also, older adults' "remembering" was much better calibrated when interference came from PI rather than from a misleading prime. False remembering was infrequent for both young and older adults. Why is presentation of a misleading prime more likely to produce capture than is PI? One possibility is that the variable mapping of stimuli and responses used by Jacoby et al. (2001) made the interfering response less compelling. In the training phase used to manipulate the dominance of a response in their experiments, one of the two possible responses for a test item was presented more frequently, but each response was presented several times. Consequently, it is likely that both young and older adults could produce both possible responses for each test item. Their ability to do so might make the cued-recall test similar to a test of recognition memory, with the result that interference was reduced, as we found in Experiment 4.

\section{Modes of Cognitive Control: Bases for False Memory}

The capture model postulates two modes of cognitive control, an early selection mode and a later evaluation mode (cf. Jacoby et al., 1999; Jacoby, Shimizu, Daniels, \& Rhodes, in press). The distinction between modes of control is similar to one made by Burgess and Shallice (1996) in their analysis of confabulation. They distinguished between a cue-specification phase, which is important for constraining the responses that come to mind, and an evaluation phase, which comes into play after a response is brought to mind. Capture by an invalid prime reflects a deficit in the early selection, cue specification phase. Rather than specifying cues in a way that restricted retrieval to earlier studied responses, as is required for recollection, older adults sometimes relied on more general cues that constrained retrieval in a way that was appropri- 
ate for producing an earlier presented word, which could be the prime.

The attribution threshold parameter in the model corresponds to an evaluation parameter that served here to evaluate whether a response was remembered but could also be used to describe the role of source identification in avoiding false memory (e.g., Lindsay, 1993) or age differences in evaluation processes, such as discounting (Hess, McGee, Woodburn, \& Bolstad, 1998; Jacoby, 1999). However, our finding that age differences in false remembering were larger for cued recall than for a recognition-memory test suggests that the means by which an item is brought to mind is important; age differences in false memory were not fully reliant on differences in evaluation processes.

Our model holds that there are two means by which false remembering arises. First, the attribution threshold parameter accounts for subjective reports in much the same way as do signal detection theory accounts of "remember" and "know" responses (e.g., Donaldson, 1996; Hirshman \& Master, 1997). That is, after having been brought to mind because of accessibility bias, a potential response is evaluated and is accepted as remembered only if it is sufficiently familiar or passes some other such criterion. By this route, presentation of an invalid prime had an effect on accessibility bias that was the same for young and older adults, but, because of a higher value of $A T$ (lower threshold), older adults were more likely to say "remember." A second route to false remembering, perhaps a more important one, was taken only by older adults - capture by an invalid prime. When captured by a prime, older adults often said "remember," which resulted in false remembering when the prime was invalid. The dramatically high false remembering by older adults found in our experiments discourages us from taking "remember" responses at face value (cf. Gardiner \& Richardson-Klavehn, 2000) as reflecting some aspect of episodic memory.

The option not to respond provides participants with a means of avoiding costly errors (Koriat \& Goldsmith, 1994, 1996). Older adults seldom took advantage of the opportunity to not respond (to pass) as a means of avoiding false recall, whereas young adults were likely to do so (Experiment 3). Similar results were found by Kelley and Sahakyan (2003). Older adults' disinclination to pass is in accord with their greater likelihood of falsely remembering words presented as invalid primes.

The possibility of two bases for false remembering raises new issues regarding the adjustment of responding to accord with risks. Such adjustment of responding has generally been cast as requiring a change in a threshold that is akin to the attribution threshold parameter in our model (e.g., Koriat \& Goldsmith, 1996). From that perspective, training older adults to better adjust their responding should focus on their ability to evaluate potential responses after they are brought to mind. However, our results suggest that deficient cue specification in the form of capture may be a more common basis for false remembering and might also be most important for failures to adjust responding to accord with risks. Perhaps training of the ability to adjust responding is better aimed at cue specification as a means of constraining whether a particular response comes to mind rather than at evaluation of responses after they have been brought to mind. More generally, manipulations of risk might influence the construal of a situation and, thereby, determine the initial candidacy of a response rather than only influencing its evaluation.

\section{Underlying Assumptions and Similarity to Other Models}

The assumptions underlying the RA model, which was extended to produce the capture model, have been extensively discussed. Most controversial has been the assumption that recollection and accessibility bias are independent (e.g., Curran \& Hintzman, 1995; Dennis \& Humphreys, 2001; Jacoby \& Shrout, 1997). Support for the independence of recollection and accessibility bias is gained from the finding in Experiment 1 that manipulating the prime influenced accessibility bias but left recollection unchanged, whereas dividing attention during study produced an opposite dissociation.

Extending the RA model to include the possibility of capture raises further questions regarding the independence of parameters. Perhaps most problematic is the independence of capture and recollection. Capture might be more likely to occur when the probability of recollection is low. Against this possibility, a preliminary experiment done in our lab (Jacoby \& Bishara, 2003) provides evidence of age differences in capture even when recollection was equated and was extremely high. We used a continuous version of the task implemented in the experiments reported here and varied the spacing between the presentation of a pair and its test. With an invalid prime at zero spacing (e.g., knee bone, bend, knee $\left.b \_n \_\right)$, the probability of mistakenly producing the misleading prime (e.g., bend) was much higher for older, as compared with young, adults (.20 vs. .01), even though use of a longer study presentation of the pair for older adults resulted in nearly perfect performance in the baseline condition for both age groups. This result shows that older adults can be captured by a misleading prime even when recollection of a correct response is very easy, suggesting that capture and recollection are independent or, at least, nearly so.

Yet another concern is whether capture and accessibility bias are independent of one another. Capture by the prime and accessibility bias differ in that capture reflects a deficit in attention and eliminates the opportunity to engage in recollection, whereas accessibility bias operates only after recollection is attempted and fails. A goal for future research is to find manipulations that produce dissociations for the capture and accessibility parameters to provide evidence for their independence.

The general notions that form the basis for the capture model (goal neglect or inhibition deficit, monitoring deficit) are common to many models of executive functions, most of which are informal ones. With regard to formal models, capture has a role that is similar to that of judgment on the basis of familiarity in the Atkinson and Juola (1974) dual-process model of recognition memory - both familiarity-based recognition judgments and capture are held to occur prior to and rule out an attempt at recollection or memory search. The accessibility bias and attribution parameters serve functions that are similar to that of strength and criterion parameters in other models (e.g., Ratcliff \& McKoon, 1995). The advantages of the capture model are that it includes different aspects of cognitive control in a single model and might, in future research, serve as a means of measuring individual differences in the contributions of those aspects to overall performance.

Are those who are vulnerable to capture in a memory task also more vulnerable to Stroop interference? Is there a relation between ability to recollect in a memory task and interference effects in 
other tasks? Questions such as these focus on correlations among model parameters for different tasks. For example, Zelazo, Craik, and Booth (2004) used the process-dissociation procedure and found that recollection showed an inverted $U$-shaped function across three age groups (8-10-year-olds vs. young adults vs. older adults), whereas estimates of automatic influences (accessibility bias) were age invariant. Significant negative correlations were found between estimates of recollection and perseveration errors on a card-sorting task.

Although the capture model extends the RA model, it is still not exhaustive with regard to the processes that might sometimes underlie memory performance. However, development of a complete model that includes all possibilities is not our goal. Rather, our aim is to develop a relatively simple model that is useful for specifying the unity and diversity of executive functions that decline with aging (cf. Miyake et al., 2000) and that can serve as a guide for the development of memory rehabilitation procedures (e.g., Jacoby et al., 1999). The capture model might also be useful for the applied purpose of identifying older adults who are most vulnerable to memory scams. Our results suggest that there is good reason to worry that older adults are more vulnerable to scams that rely on interference effects than are young adults. Further, their greater susceptibility is not simply because of age differences in original learning.

\section{References}

Arenberg, D. (1973). Cognition and aging: Verbal learning, memory, and problem solving. In C. Eisdorfer \& M. P. Lawton (Eds.), The psychology of adult development and aging (pp. 74-97). Washington, DC: American Psychological Association.

Atkinson, R. C., \& Juola, J. F. (1974). Search and decision processes in recognition memory. In R. C. Atkinson, D. H. Krantz, \& P. Suppes (Eds.), Contemporary developments in mathematical psychology: Vol. 1. Learning, memory, and thinking (pp. 243-293). San Francisco: Freeman.

Ayers, M. S., \& Reder, L. M. (1998). A theoretical review of the misinformation effect: Predictions from an activation-based memory model. Psychonomic Bulletin \& Review, 5, 1-21.

Balota, D. A., Dolan, P. O., \& Duchek, J. M. (2000). Memory changes in healthy older adults. In E. Tulving \& F. I. M. Craik (Eds.), The Oxford handbook of memory (pp. 395-409). New York: Oxford University Press.

Batchelder, W. H., \& Riefer, D. M. (1999). Theoretical and empirical review of multinomial process tree modeling. Psychonomic Bulletin \& Review, 6, 57-86.

Bekerian, D. A., \& Bowers, J. M. (1983). Eyewitness testimony: Were we misled? Journal of Experimental Psychology: Learning, Memory, and Cognition, 9, 139-145.

Belli, R. F., Windschitl, P. D., McCarthy, T. T., \& Winfrey, S. E. (1992). Detecting memory impairment with a modified test procedure: Manipulating retention interval with centrally presented event items. Journal of Experimental Psychology: Learning, Memory, and Cognition, 18, 356367.

Bodner, G. E., \& Lindsay, D. S. (2003). Remembering and knowing in context. Journal of Memory \& Language, 48, 563-580.

Brainerd, C. J., \& Reyna, V. F. (1998). When things that were never experienced are easier to "remember" than things that were. Psychological Science, 9, 484-489.

Burgess, P. W., \& Shallice, T. (1996). Confabulation and the control of recollection. Memory, 4, 359-411.

Cohen, G., \& Faulkner, D. (1989). Age differences in source forgetting: Effects of reality monitoring and on eyewitness testimony. Psychology and Aging, 4, 10-17.
Cohen, J. (1977). Statistical power analysis for the behavioral sciences (rev. ed.). New York: Academic Press.

Craik, F. I. M. (1977). Age differences in human memory. In J. E. Birren \& K. W. Schaie (Eds.), Handbook of the psychology of aging (pp. 384-420). New York: Van Nostrand.

Craik, F. I. M., \& Jennings, J. M. (1992). Human memory. In F. I. M. Craik \& T. A. Salthouse (Eds.), The handbook of aging and cognition (pp. 51-110). Hillsdale, NJ: Erlbaum.

Curran, T., \& Hintzman, D. L. (1995). Violations of the independence assumption in process dissociation. Journal of Experimental Psychology: Learning, Memory, and Cognition, 21, 531-547.

Deese, J. (1959). On the prediction of occurrence of particular verbal intrusions in immediate recall. Journal of Experimental Psychology, 58, $17-22$.

Dennis, S., \& Humphreys, M. S. (2001). A context noise model of episodic word recognition. Psychological Review, 108, 452-478.

Dodson, C. S., Prinzmetal, W., \& Shimamura, A. P. (1998). Using Excel to estimate parameters from observed data: An example from source memory data. Behavior Research Methods, Instruments \& Computers, $30,517-526$.

Donaldson, W. (1996). The role of decision processes in remembering and knowing. Memory \& Cognition, 24, 523-533.

Duncan, J. (1995). Attention, intelligence, and the frontal lobes. In M. S. Gazzaniga (Ed.), The cognitive neurosciences (pp. 721-733). Cambridge, MA: MIT Press.

Duncan, J., Emslie, H., Williams, P., Johnson, R., \& Freer, C. (1996). Intelligence and the frontal lobe: The organization of goal-directed behavior. Cognitive Psychology, 30, 257-303.

Erdfelder, E., Faul, F., \& Buchner, A. (1996). GPOWER: A general power analysis program. Behavior Research Methods, Instruments, \& Computers, 28, 1-11.

Gardiner, J. M. (1988). Functional aspects of recollective experience. Memory \& Cognition, 16, 309-313.

Gardiner, J. M., \& Richardson-Klavehn, A. (2000). Remembering and knowing. In E. Tulving \& F. I. M. Craik (Eds.), The Oxford handbook of memory (pp. 229-244). New York: Oxford University Press.

Hasher, L., \& Zacks, R. T. (1988). Working memory, comprehension, and aging: A review and a new view. In G. H. Bower (Ed.), The psychology of learning and motivation: Advances in research and theory (Vol. 22, pp. 193-225). San Diego, CA: Academic Press.

Hay, J. F., \& Jacoby, L. L. (1996). Separating habit and recollection: Memory slips, process dissociations and probability matching. Journal of Experimental Psychology: Learning, Memory, and Cognition, 22, 1323-1335.

Hay, J. F., \& Jacoby, L. L. (1999). Separating habit and recollection in young and older adults: Effects of elaborative processing and distinctiveness. Psychology and Aging, 14, 122-134.

Hess, T. M., McGee, K. A., Woodburn, S. M., \& Bolstad, C. A. (1998). Age-related priming effects in social judgments. Psychology and Aging, 13, 127-137.

Hirshman, E., \& Master, S. (1997). Modeling the conscious correlates of recognition memory: Reflections on the remember-know paradigm. Memory \& Cognition, 25, 345-351.

Jacoby, L. L. (1996). Dissociating automatic and consciously controlled effects of study/test compatibility. Journal of Memory and Language, $35,32-52$

Jacoby, L. L. (1999). Deceiving the elderly: Effects of accessibility bias in cued-recall performance. Cognitive Neuropsychology, 16, 417-436.

Jacoby, L. L., \& Bishara, A. J. (2003). [Aging and capture]. Unpublished raw data.

Jacoby, L. L., Debner, J. A., \& Hay, J. F. (2001). Proactive interference, accessibility bias, and process dissociations: Valid subjective reports of memory. Journal of Experimental Psychology: Learning, Memory, and Cognition, 27, 686-700. 
Jacoby, L. L., Jennings, J. M., \& Hay, J. F. (1996). Dissociating automatic and consciously controlled processes: Implications for diagnosis and rehabilitation of memory deficits. In D. J. Herrmann, C. L. McEvoy, C. Hertzog, P. Hertel, \& M. K. Johnson (Eds.), Basic and applied memory research: Theory in context (Vol. 1, pp. 161-193). Hillsdale, NJ: Erlbaum.

Jacoby, L. L., Kelley, C. M., \& McElree, B. D. (1999). The role of cognitive control: Early selection versus late correction. In S. Chaiken \& Y. Trope (Eds.), Dual-process theories in social psychology (pp. 383400). New York: Guilford Press.

Jacoby, L. L., Shimizu, Y., Daniels, K. A., \& Rhodes, M. G. (in press). Modes of cognitive control in recognition and source memory: Depth of retrieval. Psychonomic Bulletin \& Review.

Jacoby, L. L., \& Shrout, P. E. (1997). Toward a psychometric analysis of violations of the independence assumption in process dissociation. Journal of Experimental Psychology: Learning, Memory, and Cognition, 23, $505-510$.

Johnson, M. K., Hashtroudi, S., \& Lindsay, D. S. (1993). Source monitoring. Psychological Bulletin, 114, 3-28.

Karpel, M. E., Hoyer, W. J., \& Toglia, M. P. (2001). Accuracy and qualities of real and suggested memories: Nonspecific age differences. Journals of Gerontology, Series B: Psychological Sciences \& Social Sciences, 56B(2), 103-110.

Kausler, D. H. (1991). Experimental psychology, cognition and human aging (2nd ed.). New York: Springer-Verlag.

Kelley, C. M., \& Sahakyan, L. (2003). Memory, monitoring, and control in the attainment of memory accuracy. Journal of Memory \& Language, 48, 704-721.

Koriat, A., \& Goldsmith, M. (1994). Memory in naturalistic and laboratory contexts: Distinguishing the accuracy-oriented and quantity-oriented approaches to memory assessment. Journal of Experimental Psychology: General, 123, 297-315.

Koriat, A., \& Goldsmith, M. (1996). Monitoring and control processes in the strategic regulation of memory accuracy. Psychological Review, 103, 490-517.

Kramer, A. F., Hahn, S., Irwin, D. E., \& Theeuwes, J. (1999). Attentional capture and aging: Implications for visual search performance and oculomotor control. Psychology and Aging, 14, 135-154.

Lindsay, D. S. (1993). Eyewitness suggestibility. Current Directions in Psychological Science, 2(3), 86-89.

Lindsay, D. S., \& Jacoby, L. L. (1994). Stroop process dissociations: The relationship between facilitation and interference. Journal of Experimental Psychology: Human Perception and Performance, 20, 219-234.

Lindsay, D. S., \& Johnson, M. K. (1989). The reversed eyewitness suggestibility effect. Bulletin of the Psychonomic Society, 27(2), 111-113.

Loftus, E. F. (1975). Leading questions and the eyewitness report. Cognitive Psychology, 7, 560-572.

Loftus, E. F. (1979). Reactions to blatantly contradictory information. Memory \& Cognition, 7, 368-374.

Mäntylä, T. (1993). Knowing but not remembering: Adult age differences in recollective experience. Memory \& Cognition, 21, 379-388.

Mark, R. E., \& Rugg, M. D. (1998). Age effects on brain activity associated with episodic memory retrieval: An electrophysiological study. Brain, 121, 861-873.

McBride, D. M., \& Dosher, B. A. (1999). Forgetting rates are comparable in conscious and automatic memory: A process-dissociation study. Jour- nal of Experimental Psychology: Learning, Memory, and Cognition, 25, 583-607.

McCloskey, M., \& Zaragoza, M. S. (1985). Misleading postevent information and memory for events: Arguments and evidence against memory impairment hypotheses. Journal of Experimental Psychology: General, 114, 1-16.

McIntyre, J. S., \& Craik, F. I. M. (1987). Age differences in memory for item and source information. Canadian Journal of Psychology, 41(2), 175-192.

Mitchell, K. J., \& Johnson, M. K. (2000). Source monitoring: Attributing mental experiences. In E. Tulving \& F. I. M. Craik (Eds.), The Oxford handbook of memory (pp. 179-195). New York: Oxford University Press.

Miyake, A., Friedman, N. P., Emerson, M. J., Witzki, A. H., Howerter, A., \& Wager, T. D. (2000). The unity and diversity of executive functions and their contributions to complex "frontal lobe" tasks: A latent variable analysis. Cognitive Psychology, 41(1), 49-100.

Norman, K. A., \& Schacter, D. L. (1997). False recognition in younger and older adults: Exploring the characteristics of illusory memories. Memory \& Cognition, 25, 838-848.

Parkin, A. J., \& Walter, B. M. (1992). Recollective experience, normal aging, and frontal dysfunction. Psychology and Aging, 7, 290-298.

Perfect, T. J., \& Dasgupta, Z. R. R. (1997). What underlies the deficit in reported recollective experience in old age? Memory \& Cognition, 25, $849-858$.

Postman, L., \& Stark, K. (1969). Role of response availability in transfer and interference. Journal of Experimental Psychology, 79, 168-177.

Postman, L., \& Underwood, B. J. (1973). Critical issues in interference theory. Memory \& Cognition, 1, 19-40.

Pratt, J., \& Bellomo, C. N. (1999). Attentional capture in younger and older adults. Aging, Neuropsychology, and Cognition, 6, 19-31.

Ratcliff, R., \& McKoon, G. (1995). Bias in the priming of object decisions. Journal of Experimental Psychology: Learning, Memory, and Cognition, 21, 754-767.

Riefer, D. M., \& Batchelder, W. H. (1988). Multinomial modeling and the measurement of cognitive processes. Psychological Review, 95, 318339

Roediger, H. L., \& McDermott, K. B. (1995). Creating false memories: Remembering words not presented in lists. Journal of Memory \& Cognition, 21, 803-814.

Schneider, W. (1990). Micro experimental laboratory: Version 2. 0 [Computer software]. Pittsburgh, PA: Psychology Software Tools.

Shipley, W. C. (1986). Shipley Institute of Living Scale. Los Angeles: Western Psychological Services.

Spencer, W. D., \& Raz, N. (1995). Differential effects of aging on memory for content and context: A meta-analysis. Psychology and Aging, 10, $527-539$.

Welford, A. T. (1958). Ageing and human skill. London: Oxford University Press.

Winograd, E. (1968). List differentiation as a function of frequency and retention interval. Journal of Experimental Psychology, 76(2, Pt. 2), $1-18$.

Zacks, R. T., Hasher, L., \& Li, K. Z. H. (2000). Human memory. In F. I. M. Craik \& T. A. Salthouse (Eds.), The handbook of aging and cognition (2nd ed., pp. 293-357). Hillsdale, NJ: Erlbaum.

Zelazo, P. D., Craik, F. I. M., \& Booth, L. (2004). Executive function across the life span. Acta Psychologica, 115, 167-183. 


\section{Appendix A}

\section{Asymmetry Produced by Capture}

Unlike the recollection/accessibility-bias model, the capture model predicts asymmetry around baseline performance, such that the probability of correct recall in the baseline condition should be higher than the average of the probabilities of correct recall in the valid and invalid prime conditions. This can be formalized as

$$
\text { Asymmetry }=\text { Baseline }-[(\text { Valid }+ \text { Invalid }) / 2] .
$$

Correct recall in these three conditions can be predicted as a function of capture $(C)$, recollection $(R)$, and accessibility bias $(A)$ parameters. If we add the simplifying assumption that word generation always occurs $(W=$ 1) when accessibility bias fails, correct recall can be predicted with the capture model presented in Figure 1B. Note that accessibility bias is set to .50 for the baseline condition.

$$
\begin{gathered}
\text { Baseline }=R+(1-R) .50 . \\
\text { Valid }=C+[(1-C) R]+[(1-C)(1-R) A] . \\
\text { Invalid }=[(1-C) R]+[(1-C)(1-R)(1-A)] .
\end{gathered}
$$

By substituting Equations A2, A3, and A4 into Equation A1, we can predict asymmetry as follows:

$$
\text { Asymmetry }=(C R) / 2 \text {. }
$$

In other words, the asymmetry that makes the capture model distinctive

\begin{tabular}{|c|c|c|c|c|c|c|c|c|c|}
\hline \multirow[b]{3}{*}{ Age } & \multicolumn{9}{|c|}{ Prime condition } \\
\hline & \multicolumn{3}{|c|}{ Valid } & \multicolumn{3}{|c|}{ Baseline } & \multicolumn{3}{|c|}{ Invalid } \\
\hline & $\mathrm{R}$ & $\mathrm{F}$ & $\mathrm{G}$ & $\mathrm{R}$ & $\mathrm{F}$ & $\mathrm{G}$ & $\mathrm{R}$ & $\mathrm{F}$ & G \\
\hline \multicolumn{10}{|c|}{ Experiment 2} \\
\hline \multicolumn{10}{|c|}{ Correct recall } \\
\hline Young & .38 & .29 & .21 & .36 & .20 & .14 & .30 & .14 & .08 \\
\hline Older & .77 & .12 & .04 & .58 & .07 & .04 & .24 & .05 & .02 \\
\hline \multicolumn{10}{|c|}{ False recall } \\
\hline Young & .01 & .05 & .04 & .04 & .12 & .12 & .04 & .18 & .26 \\
\hline Older & .03 & .02 & .01 & .13 & .08 & .06 & .43 & .16 & .09 \\
\hline
\end{tabular}
from the recollection/accessibility-bias model should be most apparent when both capture and recollection occur with high probability.

\section{Appendix B}

Probability of Subjective Reports in Experiments 2 and 4

Experiment 4

\begin{tabular}{llllllllll} 
Correct recall & & & & & & & & & \\
$\quad$ Young & .44 & .21 & .12 & .44 & .21 & .15 & .46 & .21 & .13 \\
$\quad$ Older & .54 & .17 & .15 & .50 & .14 & .14 & .39 & .12 & .17 \\
False recall & & & & & & & & & \\
$\quad$ Young & .02 & .08 & .13 & .02 & .08 & .10 & .02 & .09 & .10 \\
$\quad$ Older & .02 & .05 & .07 & .05 & .07 & .10 & .09 & .08 & .14 \\
\hline
\end{tabular}

Note. $\mathrm{R}=$ "remember"; $\mathrm{F}=$ "familiar"; $\mathrm{G}=$ "guess." 